\title{
Metastable Secondary Structures in Ribosomal RNA: A New Method for Analyzing the Titration Behavior of rRNA
}

\author{
ARNOLD REVZIN, * EBERHARD NEUMANN, and \\ AHARON KATCHALSKY $\dagger \dagger$ Polymer Department, The Weizmann \\ Institute of Science, Rehovot, Israel and Max-Planck-Institut für \\ Biophysikalische Chemie, Göttingen, Germany
}

\begin{abstract}
Synopsis
The pH titration behavior of $E$. coli rRNA in the acid range has been analyzed by combining spectrophotometric and potentiometric titration data. The "simplest" model for the system, which considers as possible reactions the protonation of adenine (A), cytosine $(\mathrm{C})$, and guanine $(\mathrm{G})$ residues along with the opening of $\mathrm{A} \cdot \mathrm{U}$ and $\mathrm{G} \cdot \mathrm{C}$ base pairs, does not adequately account for the titration properties. It is postulated that extra reactions may occur in addition to those in the "simplest" model, and a new analytical method was developed to deal with this situation. Our approach yields the ultraviolet spectral changes which accompany the extra reactions, from which the nature of these reactions can in principle be deduced. The calculations also give, at each $\mathrm{pH}$, the extents of the extra reactions as well as the extents of those reactions which comprise the "simplest" model.

We infer that in acidic RNA solutions of $0.1 M$ ionic strength there occur at least two extra reactions, each of which involves $\mathrm{G}$ residues. We propose that in the $\mathrm{pH}$ range 6.0 $\geq \mathrm{pH} \geq 3.8$ triple-stranded helical sequences, presumably protonated $\mathrm{G} \cdot \mathrm{C} \cdot \mathrm{G}$, are formed. These regions are replaced at lower $\mathrm{pH}$ by acid-stable structures involving $\mathrm{G} \cdot \mathrm{G}$ and $\mathrm{A} \cdot \mathrm{A}$ base pairs. In solutions of lower ionic strength $(I=0.01 M)$ no triple strands are formed, but $\mathrm{G} \cdot \mathrm{G}$ and $\mathrm{A} \cdot \mathrm{A}$ regions seem to develop even at $\mathrm{pH}$ values as high as 6.0. At $I=0.1 M$, an acid-base titration cycle between $\mathrm{pH} 7$ and 2.8 is not reversible; rRNA shows true hysteresis behavior. We conclude that in ribosomal RNA's, which are generally G-rich, guanine residues may participate in hitherto unpredicted conformations, some of which may be metastable while others are equilibrium structures.
\end{abstract}

\section{INTRODUCTION}

Ribosomal RNA exhibits hysteresis in its $\mathrm{pH}$ titration in the acid range. ${ }^{1}$ That is, ultraviolet absorbance or proton-binding data lie on one curve as the $\mathrm{pH}$ is decreased from neutrality, but follow a different curve when base is added to a low-pH solution. This phenomenon has been discussed in a

* Address correspondence to A.R. at the Institute of Molecular Biology, University of Oregon, Eugene, Oregon 97403.

$\dagger$ This work was initiated under the guidance and inspiration of the late Aharon Katchalsky. We regret that the final form of the manuscript did not benefit from his critical insight and comments.

(C) 1973 by John Wiley \& Sons, Inc. 
previous paper ${ }^{1}$ in terms of metastable secondary structures which are formed at low $\mathrm{pH}$. In order to perform a quantitative analysis of the hysteresis phenomenon, it was found necessary to develop new procedures for deriving information about nucleic acid conformation from spectrophotometric and potentiometric titration data. In this report we present our new method, which resembles, in some respects, that of $\operatorname{Cox}^{2,3}$ who attempted to sort the spectral changes upon titration (or heating) of RNA into contributions from the absorbance increments accompanying each of the processes which occur. We have considerably modified and extended Cox's approach and have applied our method to new titration data for RNA.

We will primarily be concerned with structural changes occurring as the $\mathrm{pH}$ is lowered from $\mathrm{pH} 7$. The starting structure of rRNA is assumed to be that which has emerged from various studies at $\mathrm{pH} 7$, namely, a single polymeric chain containing short base-paired regions alternating with stretches in which the bases are not paired. ${ }^{2,4-6}$ Approximately 60-80\% of the residues are involved in double-helical regions, with about $55 \%$ of the paired bases being G.C. (Abbreviations used: A, adenine; U, uracil; $\mathrm{G}$, guanine; $\mathrm{C}$, cytosine; $\mathrm{T}$, thymine.) The observed changes in the absorbance and in the number of protons bound as the $\mathrm{pH}$ is lowered are composites of changes from several processes. Even the simplest model for the system must involve at least five reactions: the opening of $A \cdot U$ and $\mathrm{G} \cdot \mathrm{C}$ base pairs and the protonation of $\mathrm{A}, \mathrm{C}$, and $\mathrm{G}$ residues. ${ }^{7}$ We may neglect protonation of the polynucleotide backbone phosphates in the $\mathrm{pH}$ range covered in this study. ${ }^{8}$ The "simplest" model does not provide for formation of any acid-stable structures. Thus, our hysteresis results ${ }^{1}$ imply that it will not be a realistic model for RNA in solutions of low $\mathrm{pH}$. Furthermore, as we shall see, a careful examination of the data at higher pH values indicates that the "simplest" model will not be adequate in this $\mathrm{pH}$ range either.

Previous quantitative treatments of RNA titration and melting results have involved straightforward analysis of the data in terms of contributions from the reactions of the simplest model. ${ }^{2,3}$ We shall show that, as expected, this procedure is not adequate for rRNA at acidic $\mathrm{pH}$. We present a new calculation method which assumes the presence of at least one unspecified "extra" reaction in addition to those of the simplest model. Our approach yields not only the extents of the several reactions at each $\mathrm{pH}$ value, but also gives a spectral characterization of the additional process(es). The calculations lead us to propose the existence of at least two acid-stable conformations, one of which corresponds to the metastable structure which we discussed in our previous article. ${ }^{1}$ An important feature of our new method is that it predicts spectral characteristics for the metastable structure which are consistent with the experimental data presented in that article.

While the $\mathrm{pH}$ values used in this study are not physiological, it is conceivable that rRNA, when combined with proteins to form the ribosome, 
might assume one or more of the proposed acid-stable structures. Furthermore, the $\mathrm{pH}$-induced conformational changes considered here may be related to temperature- and ionic strength-induced structural transitions seen in $5 \mathrm{~S}-\mathrm{RNA}^{9}$ and in $\mathrm{tRNA}^{10}$, the nature of which is not yet fully elucidated.

\section{EXPERIMENTAL}

The rRNA was a mixture of $16 \mathrm{~S}$ and $23 \mathrm{~S}$ particles, from $E$. coli strain MRE600. Details of RNA preparation as well as a description of buffers and of titration procedures have been given previously. ${ }^{1}$

\section{RESULTS}

The results of the potentiometric titrations are presented in Figure 1, while spectrophotometric data are given in Figures 2 and 3 . Absorbance results are presented for two ionic strengths $(I=0.1 M$ and $0.01 M \mathrm{NaCl})$. It is seen from Figure 1 that upon titration with acid from neutral solution one curve is obtained (the "acid branch" of the hysteresis loop), while a different curve (the "base branch") is followed upon addition of base to a low $\mathrm{pH}$ solution. Similar results are found in the optical titrations 1 -we present here only the acid branch data, for which most of our calculations will be performed. We have previously reported that absence of $\mathrm{Mg}^{++}$ ions causes the hysteresis to disappear, giving. only one titration curve, which coincides with the acid.branch (Fig. 2). In the presence of $\mathrm{Mg}^{++}$, no hysteresis loop is observed unless the $\mathrm{pH}$ is reduced at least to below $\mathrm{pH}$ 3.8. . We will make use of certain features of the hysteresis cycle in the analysis which follows.

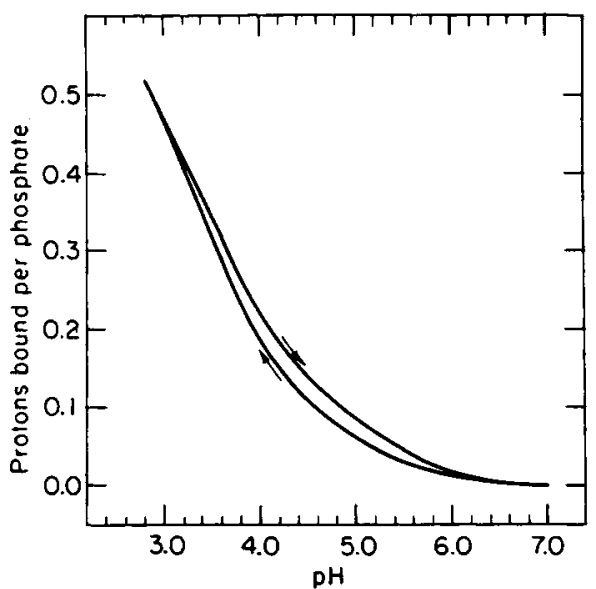

Fig. 1. Potentiometric titration of unfractionated $E$. coli rRNA. Experimental conditions: $T=20^{\circ} \mathrm{C}$, buffer $0.099 \mathrm{M} \mathrm{NaCl}, 0.001 M \mathrm{Na}$ cacodylate, $\mathrm{RNA}$ concentration $\sim 4 \times 10^{-3} M[\mathrm{P}]$. The lower curve is the acid branch, the upper curve the base branch from $\mathrm{pH} 2.8$. 

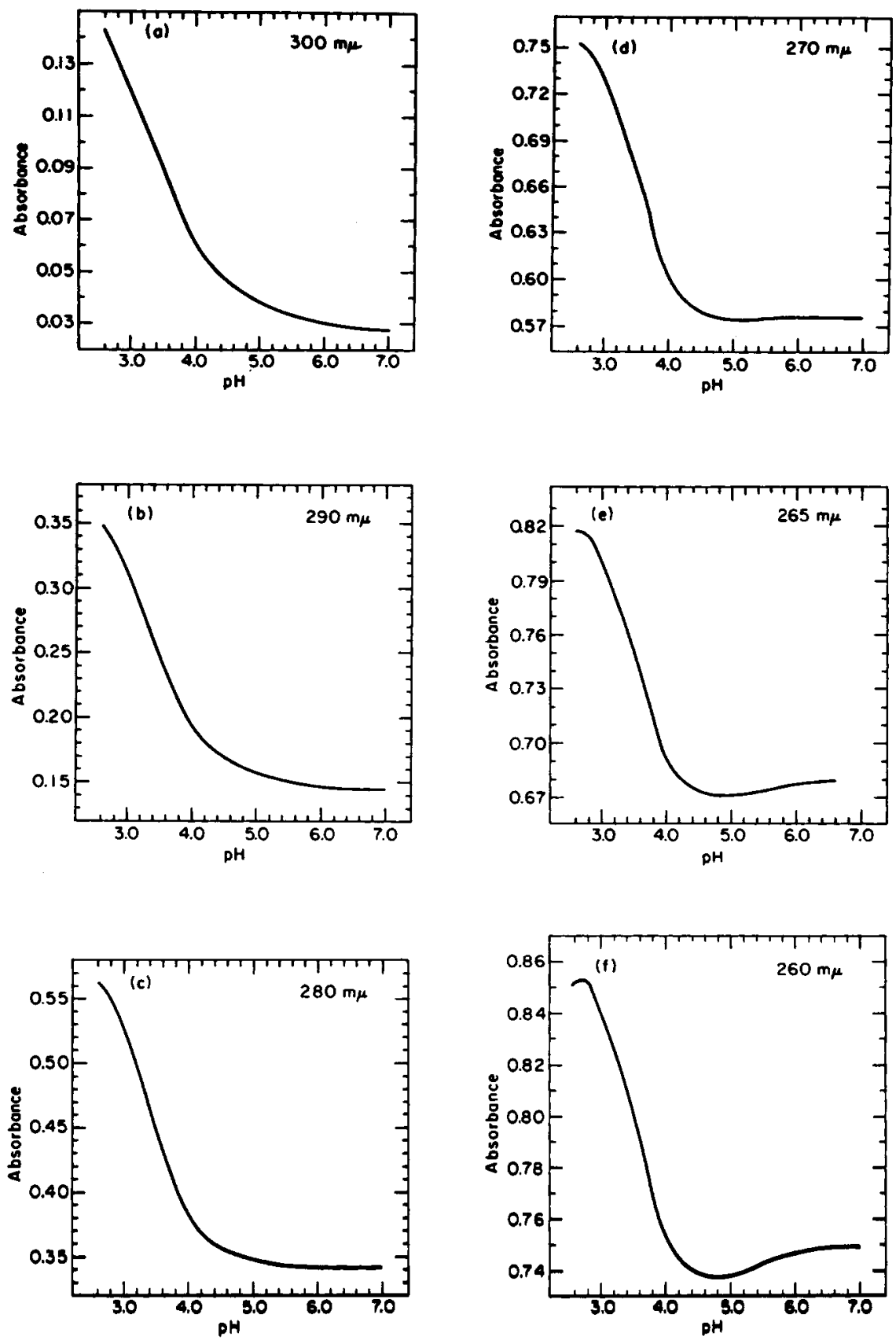

Fig. 2. Spectrophotometric titration of unfractionated $E$. coli rRNA. Experimental conditions: $T=20^{\circ} \mathrm{C}$, buffer $0.099 \mathrm{M} \mathrm{NaCl}, 0.001 \mathrm{M}$ Na cacodylate $\left(\sim 2 \times 10^{-4} \mathrm{M}\right.$ $\mathrm{MgCl}_{2}$ ). All data have been converted to a standard RNA concentration of $10^{-4} \mathrm{M}[\mathrm{P}]$. Each curve shown is the acid branch of the hysteresis loop. 

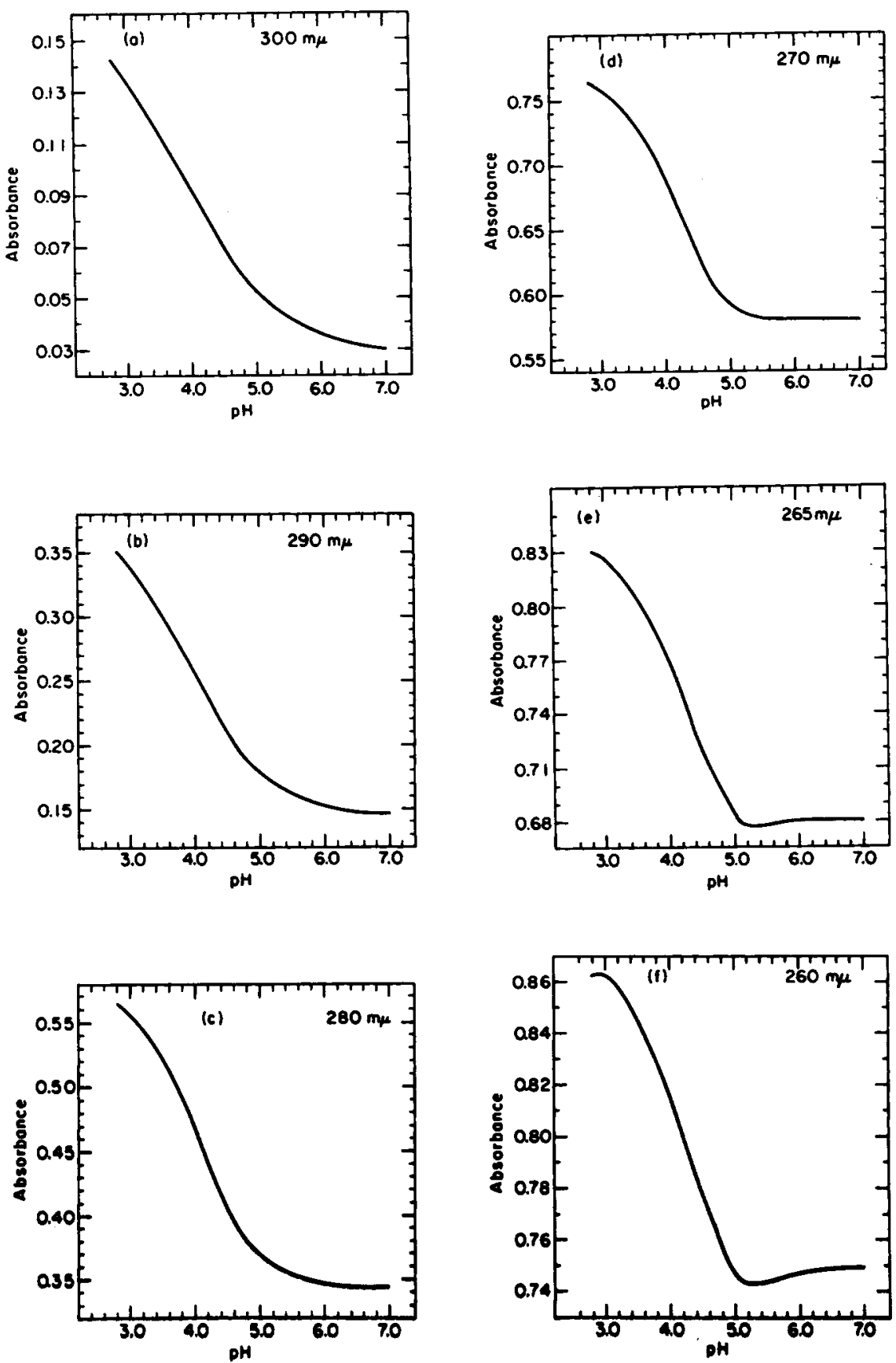

Fig. 3. Spectrophotometric titration of unfractionated E. coli rRNA. Experimental conditions: $T=20^{\circ} \mathrm{C}$, buffer $0.009 M \mathrm{NaCl}, 0.001 \mathrm{M} \mathrm{Na}$ cacodylate. All data have been converted to a standard RNA concentration of $10^{-4} M$ [P]. Each curve shown is the acid branch of the hysteresis loop. 
We also note evidence that the events which occur in acidic solution are not caused by aggregation of the RNA molecules. This important conclusion is based on sedimentation measurements ${ }^{1}$ and on the observation that the hysteresis phenomenon exists over a wide range of RNA concentrations. Thus, analysis of our titration data yields information about intramolecular conformational changes in rRNA.

\section{Titration Data in the pH Range $5<\mathrm{pH}<7$}

Close inspection of the absorbance and proton-binding data in Figures 1 and 2 indicates, even without calculations, that the "simplest" model for the system will not hold at high $\mathrm{pH}$, in $I=0.1 M$ solutions. This rather unexpected observation will be discussed in some detail because, due to the assumptions inherent in analysis of optical data, we do not wish to lightly reject what seems to be the most likely "simplest" model.

The many previous studies of RNA and synthetic polynucleotides imply that, of the reactions in the "simplest" model, the most probable at high $\mathrm{pH}$ are the protonation of $\mathrm{C}$ and $\mathrm{A}$ residues. ${ }^{8}$ Cox $^{3}$ has estimated that the pK for cytosine residues in unstacked single-stranded (amorphous) segments of RNA is about 4.7, compared with 4.3 for CMP.3,11 (Abbreviations used: CMP, cytidine-5'-phosphate; AMP, adenosine-5'-phosphate; GMP, guanosine-5'-phosphate.) If one attributes the increase in pK of 0.4 unit to the "polyelectrolyte effect" of the phosphate backbone, ${ }^{8,12}$ then one can assign a value for the $\mathrm{pK}$ (in single-stranded regions) of adenine residues to be about 4.2 (cf. 3.8 for $A M P^{11}$ ) and for guanine residues to be about 2.8 (cf. 2.4 for GMP ${ }^{13,14}$ ). A residue participating in a Watson-Crick base pair will accept protons only at a $\mathrm{pH}$ lower than that for the corresponding amorphous residue, ${ }^{3}$ if indeed protons can at all be bound to such paired residues in polyribonucleotides.

The data in Figures 2a-2c show significant increases in absorbance at $\lambda=300 \mathrm{~m} \mu$ and $\lambda=290 \mathrm{~m} \mu$ over the $\mathrm{pH}$ range $7-5$ on the acid branch, but only a small increase at $\lambda=280 \mathrm{~m} \mu$. We shall see below that the spectral changes accompanying the protonation of adenine are negligible. It will also be shown that when cytosine residues are protonated the extinction changes at $\lambda=290 \mathrm{~m} \mu$ and $\lambda=280 \mathrm{~m} \mu$ are about equal. Thus, we might suspect the presence of another reaction which lowers the absorbance at $\lambda=280 \mathrm{~m} \mu$. Such a reaction should also explain the decrease in absorbance at $\lambda=270,265$, and $260 \mathrm{~m} \mu$.

That $\mathrm{C}$ residues are indeed being protonated is evident from the data for the number of protons bound per phosphate $\left(\mathrm{H}^{+} /[\mathrm{P}]\right)$ versus $\mathrm{pH}$ (Fig. 1). ([P] denotes phosphate residues of the polynucleotide backbone.) The value of $\mathrm{H}^{+} /[\mathrm{P}]$ at about $\mathrm{pH} 5$ is, perhaps, higher than one might have expented on the basis of the $\mathrm{p} K$ values given above. It should be noted that the binding of significant numbers of protons at high $\mathrm{pH}$ was also observed by Cox and Littauer. ${ }^{7}$ Proteins, which were present to $<1 \%$, cannot account for the proton-binding results. The $\mathrm{H}^{+} /[\mathrm{P}]$ data are satisfactorily explained, however, if roughly equal amounts of $\mathrm{A}$ and 
$\mathrm{C}$ are protonated in the $\mathrm{pH}$ range 7-5. This is likely to be the case because, while the $\mathrm{pK}$ of $\mathrm{C}$ exceeds that of $\mathrm{A}$, the fractions of amorphous residues which are $\mathrm{C}$ and $\mathrm{A}$ can be shown to be about $9 \%$ and $31 \%$, respectively (based on our assumptions about helical fractions at $\mathrm{pH} 7$ ). These numbers will, of course, vary if we use different values for the helical fractions at $\mathrm{pH} 7$ but any reasonable choices will not contradict our conclusion that protonation of $\mathrm{A}$ alone cannot give the observed $\mathrm{H}^{+} /[\mathrm{P}]$ results, and thus there must be substantial protonation of $\mathrm{C}$ residues. [The number of amorphous $\mathrm{A}$ residues could be increased by opening of $\mathrm{A} \cdot \mathrm{U}$ base pairs, but this would give increases in $A_{270}, A_{265}$, and $A_{260}$ (see below), contrary to observation.]

Thus, for solutions of $0.1 \mathrm{M}$ ionic strength the absorbance changes for rRNA in the $\mathrm{pH}$ range $7-5$ are not those from the predicted protonation of $\mathrm{C}$. We note that this is not the case for tRNA. We report below that upon titration of unfractionated $E$. coli tRNA, spectral changes at high $\mathrm{pH}$ values can be accounted for by cytosine protonation alone. We conclude, then, that at high $\mathrm{pH}$ there must occur in rRNA (but not in tRNA) some hitherto unexpected reaction(s).

\section{Quantitative Analysis of the "Acid Branch" of the Titration Cycle}

The measured number of protons bound is the sum of the numbers bound to A, C, and $\mathrm{G}$ residues. Likewise, for each wavelength measured we may formally represent the measured absorbance change, $\Delta A_{\lambda}(\mathrm{per} \mathrm{cm})$, at each $\mathrm{pH}$ by an equation of the form ${ }^{3,15}$

$$
\Delta A_{\lambda}=\sum_{i} C_{i} \epsilon_{i}^{\lambda} \cdot \Delta \xi_{i}
$$

where $\Delta$ refers to changes between $\mathrm{pH} 7$ and the $\mathrm{pH}$ of interest, and the summation is over all processes to be considered. In Eq. (1), $C_{i}$ is the concentration of a base or base pair involved in process $i, \epsilon_{i}^{\lambda}$ is the change in extinction (on a molar basis) accompanying reaction $i$, and $\xi_{i}$ is the fractional extent to which reaction $i$ has proceeded. For example, if $i$ represents the protonation of $\mathrm{G}$ residues,

$$
\mathrm{G}+\mathrm{H}^{+}=\mathrm{GH}^{+}
$$

then

$$
\begin{aligned}
C_{\mathrm{G}} & =\text { overall concentration of } \mathrm{G} \text { residues in solution } \\
\epsilon_{\mathrm{GH}^{+}}^{\lambda} & =\underset{\text { protonated }}{\text { form }}-\epsilon_{\text {unprotonated }}^{\lambda} \\
\Delta \xi_{\mathrm{GH}} & \text { form } \\
& \text { difference in degree of ionization of } \mathrm{G} \text { between } \mathrm{pH} 7 \text { and the } \\
& \mathrm{pH} \text { of interest. }
\end{aligned}
$$

Thus the product $C_{\mathrm{G}} \cdot \Delta \xi_{\mathrm{GH}}+$ equals the total number of $\mathrm{G}$ residues which have been protonated as a result of the $\mathrm{pH}$ change.

Our analytical procedure is based largely on equations of type (1) from which we extract values of the extents of reaction, $\Delta \xi_{i}$. We must thus 
carefully consider how well equations of this form may be expected to approximate reality.

\section{Validity of Eq. (1)}

Single-Strand Stacking. The summation in Eq. (1) does not directly provide for any contributions to $\Delta A_{\lambda}$ from changes in the extent of singlestrand base stacking which may occur as the $\mathrm{pH}$ is lowered. (Some effects of stacking might conceivably have been incorporated into the extinction changes for base pair opening, $\epsilon_{\mathrm{AU}}^{\lambda}$ and $\epsilon_{\mathrm{GC}}^{\lambda}$, but these will be estimated for transitions in which the opened bases are totally unstacked.) Gratzer $^{16}$ and Boedtker ${ }^{17}$ have concluded from optical rotatory dispersion and absorbance data that while there is probably an appreciable amount of

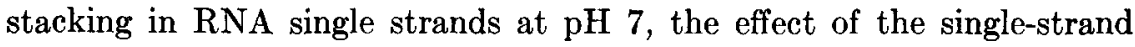
stacks on the absorbance is quite small. The degree of single-strand stacking in RNA will be considerably lower than that found in the homopolynucleotides poly $(\mathrm{A})$, poly $(\mathrm{C})$, and poly $(\mathrm{G})$, since evidence from di- and trinucleotide studies implies that certain bases tend to cause destacking when part of heterogeneous sequences. ${ }^{18,18}$ As the $\mathrm{pH}$ is lowered, doublehelical regions in RNA will break down to single strands, thus providing more bases which could potentially be stacked. However, the small hypochromism from such stacking will be reduced by the tendency of protonated residues to destack. ${ }^{18,20}$ Furthermore, at acidic $\mathrm{pH}$ values the hypochromic contributions from those bases which were (partially) stacked at $\mathbf{p H} 7$ will be lessened due to $\mathrm{H}^{+}$-induced destacking. Thus, while we do not quantitatively account for changes in the degree of stacking as the $\mathrm{pH}$ is decreased, it appears that we are justified in neglecting this effect.

Additivity of Spectral Changes for Simultaneous Processes. Implicit in Eq. (1) is the assumption that spectral changes arising from the several molecular processes may be combined linearly to yield the observed $\Delta A_{\lambda}$. This assumption appears valid for the opening of base pairs in both DNA ${ }^{21}$ and in RNA's. ${ }^{22-24}$ Spectral changes upon ionization are also likely to contribute to the total $\Delta A_{\lambda}$ in an additive manner.

End Effects. A dependence of hypochromicity upon chain length for short helixes was attributed by Rich and Tinoco ${ }^{25}$ to "fraying" at the ends of the double helixes. The effect of "frayed" ends is, of course, larger for molecules with numerous short helical stretches, and it may mean that the estimates of total helical content in RNA at $\mathrm{pH} 7$ are somewhat in error. It will be seen below that such errors will influence our quantitative results but not our qualitative conclusions. We assume that the "frayed" end of a helical segment behaves as if it has "partial" base pairs, whose spectral contribution is linearly related both to the fractions of time the base pair spends in the closed and open configurations, and to the spectral changes which accompany the opening of such a base pair in a full double-helical region.

Thus, under the above assumptions we will use Eq. (1) to represent formally the complex optical changes which accompany titration of RNA. 
The applicability of this equation will then depend on our evaluation of the quantities $\epsilon_{i}^{\lambda}$ and on whether we have included all appropriate processes in the summation.

\section{Evaluation of Extinction Changes, $\epsilon_{i}^{\lambda}$}

We now turn to the task of determining, by critical analysis of data in the literature, values for the extinction changes accompanying each process in our molecular model. These changes for five particular reactions are very important for our analysis so they will be discussed in some detail. The values actually used in our calculations are given in Table I.

TABLE I

Extinction Changes, $\epsilon_{i}^{\lambda}$, Accompanying the Reactions of the "Simplest" Titration Modela

\begin{tabular}{|c|c|c|c|c|c|}
\hline \multirow[b]{2}{*}{$\lambda, \mathrm{m} \mu$} & & \multicolumn{4}{|c|}{ Reaction } \\
\hline & & $\underset{\mathrm{CH}}{\mathrm{C}+\mathrm{H}^{+}}=$ & $\underset{\mathrm{GH}^{+\mathrm{b}}}{\mathrm{G}+\mathrm{H}^{+}=}$ & $\begin{array}{l}\mathrm{G} \cdot \mathrm{C}= \\
\mathrm{G}+\mathrm{C}^{\mathrm{c}}\end{array}$ & $\begin{array}{l}A \cdot U= \\
A+U^{c}\end{array}$ \\
\hline 300 & $\begin{array}{l}\epsilon_{i}^{300} \times 10^{-3} \\
C_{i} \epsilon_{i}^{30} 0\end{array}$ & $\begin{array}{l}4.0 \\
0.087\end{array}$ & $\begin{array}{l}1.6 \\
0.050\end{array}$ & $\begin{array}{l}0.0 \\
0.0\end{array}$ & $\begin{array}{l}0.0 \\
0.0\end{array}$ \\
\hline 290 & $\begin{array}{l}\epsilon_{i}^{290} \times 10^{-3} \\
C_{i} \epsilon_{i}^{290}\end{array}$ & $\begin{array}{l}7.9 \\
0.172\end{array}$ & $\begin{array}{l}1.9 \\
0.060\end{array}$ & $\begin{array}{l}2.4 \\
0.052\end{array}$ & $\begin{array}{l}0.0 \\
0.0\end{array}$ \\
\hline 280 & $\begin{array}{l}\epsilon_{i}^{280} \times 10^{-3} \\
C_{i} \epsilon_{i}^{280}\end{array}$ & $\begin{array}{l}6.1 \\
0.133\end{array}$ & $\begin{array}{l}0.0 \\
0.0\end{array}$ & $\begin{array}{l}6.4 \\
0.140\end{array}$ & $\begin{array}{l}0.0 \\
0.0\end{array}$ \\
\hline 270 & $\begin{array}{l}\epsilon_{i}^{270} \times 10^{-3} \\
C_{i} \epsilon_{i}^{2} 70\end{array}$ & $\begin{array}{l}1.9 \\
0.041\end{array}$ & $\begin{array}{l}-0.9 \\
-0.030\end{array}$ & $\begin{array}{l}5.6 \\
0.122\end{array}$ & $\begin{array}{l}5.1 \\
0.127\end{array}$ \\
\hline 265 & $\begin{array}{l}\epsilon_{i}^{265} \times 10^{-3} \\
C_{i} \epsilon_{i}^{265}\end{array}$ & $\begin{array}{l}0.0 \\
0.0\end{array}$ & $\begin{array}{l}0.0 \\
0.0\end{array}$ & $\begin{array}{l}3.7 \\
0.081\end{array}$ & $\begin{array}{l}8.1 \\
0.203\end{array}$ \\
\hline 260 & $\begin{array}{l}\epsilon_{i}^{2} 600 \times 10^{-3} \\
C_{i} \epsilon_{i}^{2} \quad 00\end{array}$ & $\begin{array}{l}-1.3 \\
-0.028\end{array}$ & $\begin{array}{l}0.0 \\
0.0\end{array}$ & $\begin{array}{l}3.3 \\
0.072\end{array}$ & $\begin{array}{l}8.6 \\
0.216\end{array}$ \\
\hline
\end{tabular}

- Values of $\epsilon$ for A protonation are taken to be zero at all wavelengths of interest.

b Values of $\epsilon$ for $\mathrm{C}$ and $\mathrm{G}$ protonation reactions are per mole of nucleotide residues.

- Values of $\epsilon$ for $\mathrm{G} \cdot \mathrm{C}$ and $\mathrm{A} \cdot \mathrm{U}$ base pair opening are per mole of base pairs.

\section{Extinction Changes upon Opening of $A \cdot U$ and $G \cdot C$ Base Pairs}

We seek values for the extinction changes, $\epsilon_{\mathrm{AU}}^{\lambda}$ and $\epsilon_{\mathrm{GC}}^{\lambda}$, which accompany the reactions $\mathrm{A} \cdot \mathrm{U}=\mathrm{A}+\mathrm{U}$ and $\mathrm{G} \cdot \mathrm{C}=\mathrm{G}+\mathrm{C}$. The unpaired bases in the final state are taken to be completely unstacked. These $\epsilon_{i}^{\lambda}$ values were taken from the work of Cox, ${ }^{26}$ who derived them from spectral analysis of two species of double-helical RNA. (Small values given by $\mathrm{Cox}$ for $\epsilon_{\mathrm{AU}}$ at $\lambda=280,290$, and $300 \mathrm{~m} \mu$ are neglected.) These $\epsilon_{i}^{\lambda}$ are likely to approximate reality more closely than those deduced from model polynucleotide systems ${ }^{23,27,28}$ because (a) they are derived from heterogeneous nucleic acids and thus may average out any sequence dependences which might be present, and (b) their evaluation is not hindered by self-association or extensive stacking interactions of the homopolynucleotides such as poly $(\mathrm{G})$ or poly $(\mathrm{A})$. In any case, Cox's values for $\epsilon_{\mathrm{AU}}^{\lambda}$ and $\epsilon_{\mathrm{GC}}^{\mathrm{G}}$ do not differ greatly from those derived from model systems.

\section{Extinction Changes upon the Protonation of $A, C$, and $G$ Residues}

It has generally been assumed that the spectral changes accompanying protonation of the mononucleotides can be applied without modification to the protonation of bases in 
RNA, and that the ionization spectra are the same whether the base is in a single- or double-stranded region. We have checked this assumption using data available from the literature, and we find that it is valid for the wavelengths which are used in this study.

Extinction Changes Accompanying the Reaction $\mathbf{A}+\mathbf{H}^{+}=\mathbf{A H} \mathbf{H}^{+}$. The protonated and unprotonated forms of AMP show little difference in ultraviolet absorbance over the range $230<\lambda<300 .{ }^{29}$ It is difficult to check whether this is true for AMP incorporated into polynucleotides because poly(A) undergoes a coil-helix transition with formation of $\mathrm{A} \cdot \mathrm{A}$ double helixes at about $\mathrm{pH} 5.5-6.0^{30,31}$ Nevertheless, spectrophotometric titrations of poly(A) in this laboratory (M. Spodheim, unpublished data) show only very small changes in absorbance at all $\lambda$ both above and below the $\mathrm{pH}$ range of the coil-helix reaction. It is known that single-stranded poly(A) binds a few protons before undergoing the transition, and that many protons are added to double-helical poly(A) as the $\mathrm{pH}$ is lowered. ${ }^{31,32}$ Thus, these data imply that we can neglect spectral changes due to adenine protonation regardless of the structure in which the $\mathrm{A}$ is involved. The assumption that $\epsilon_{\mathrm{AII}^{+}}=0$ at all wavelengths simplifies Eq. (1), but also means that the extent of A protonation cannot be derived spectrophotometrically but must be inferred from the proton-binding results.

Extinction Changes Accompanying the Reaction $\mathbf{C}+\mathbf{H}^{+}=\mathbf{C H}^{+}$. We wish to check if the spectral changes upon cytosine protonation are independent of whether the base is in a mononucleotide (CMP) or is in a single- or double-stranded polynucleotide. Spectral data for the protonation of $\mathrm{C}$ residues in single-stranded polymers could come from studies on an amorphous polynucleotide, poly(UC) (CMP:UMP $=1: 8$ ). $\mathrm{Cox}^{3}$ has reported preliminary titrations with this material, but spectral data are not presented. The extensive titration results of Hartman and $\mathrm{Rich}^{33}$ can be used to derive the protonation spectrum of cytosine in poly $(\mathrm{C})$. Treatment of the data is complicated by optical changes accompanying the formation of double-stranded poly $(\mathrm{C})$, at about $\mathrm{pH} 5.6$ (in $0.1 M \mathrm{NaCl}$ solution, $T=25^{\circ} \mathrm{C}$ ).

Only a few protons are bound to single-stranded poly $(\mathrm{C})$ prior to the coil-helix reaction, so accurate data for the protonation spectrum of $\mathrm{C}$ in the single-stranded form are not available. There is, however, a substantial uptake of protons by double-helical poly $(\mathrm{C})$ as the $\mathrm{pH}$ is lowered from $\mathrm{pH} 5.5$ to about $\mathrm{pH}$ 3.2. It appears that the double helix begins to be destabilized when the number of protons bound exceeds one per base pair (this occurs at about $\mathrm{pH} 4.5$ ) and eventually the double helix is disrupted at about pH 3. It is not entirely correct to consider that the ultraviolet absorbance data which Hartman and $\mathrm{Rich}^{33}$ give for the $\mathrm{pH}$ region 5.5-3.2 reflect only protonation of $\mathrm{C}$ in the double helix, for these authors also mention X-ray studies ${ }^{34}$ which indicate structural differences between poly $(\mathrm{C})$ double helixes at $\mathrm{pH} 5.5$ and 4.0. Thus, part of the optical density change may arise from destabilization of the helical structure at low $\mathrm{pH}$. Nevertheless, such structural changes should be small between $\mathrm{pH} 5.5$ and 4.5, and combination of the proton binding and spectral data permits evaluation of molar extinction changes upon protonation of cytosine in the $\mathrm{C} \cdot \mathrm{C}$ double helix. It is found that these $\epsilon_{\mathrm{CH}}+$ values are close to the values for $\mathrm{CMP}^{29}$ except at $\lambda=300 \mathrm{~m} \mu$. Since there is no obvious way to choose between the possible values of $\epsilon_{\mathrm{CH}}+$ at $\lambda=300 \mathrm{~m} \mu$, some calculations for RNA were made using different values for this quantity (see below). As was the case for adenine, we do not have a direct measure of the cytosine protonation spectrum when the base is in a single-stranded polymer. Nevertheless, the data of Hartman and $\mathrm{Rich}^{33}$ for $\mathrm{C}$ in a more complex double-helical structure imply that the CMP protonation spectrum may be a good approximation for cytosine in all polynucleotide forms.

To conclude this section, we note the recent work of Cox, Kanagalingam, and Sutherland ${ }^{35}$ in which is given the absorbance spectrum obtained upon heating to $95^{\circ} \mathrm{C}$ a double-helical virus-like RNA at $\mathrm{pH}$ 3.6. The authors quantitatively account for this spectrum by summing contributions from the opening of $\mathrm{A} \cdot \mathrm{U}$ and $\mathrm{G} \cdot \mathrm{C}$ base pairs, and from the protonation of $\mathrm{C}$ residues, using data for $\mathrm{CMP}$ and an estimated value for the extent of cytosine protonation. Further support for the use of the CMP protonation 
difference spectrum for cytosine in polynucleotides is derived from our titration of tRNA. As the $\mathrm{pH}$ is decreased from $\mathrm{pH} 7$ to $\mathrm{pH} 5$, the most likely reaction occurring in tRNA solutions is the ionization of $\mathrm{C}$ residues. We found that absorbance changes in this $\mathbf{p H}$ range parallel rather closely the changes seen upon protonation of CMP.

Extinction Changes Accompanying the Reaction $\mathbf{G}+\mathbf{H}^{+}=\mathbf{G H}$. The tendency of oligo and poly $(\mathrm{G})$ to aggregate to helical structures involving an undetermined number of strands ${ }^{13,36,37}$ has resulted in a paucity of spectral data for the protonation of guanine in polynucleotides. Therefore, we assume that the GMP protonation difference spectrum $^{20}$ applies to $\mathrm{G}$ in RNA molecules, an assumption which is quite reasonable in light of our observations that the AMP and CMP spectra do adequately represent the situation for the protonation of $\mathrm{A}$ and $\mathrm{C}$ in more complex structures.

This completes our choice of spectral parameters for five important reactions which will occur as RNA is titrated with acid. The values of these parameters are crucial for the quantilative analysis to follow. We will defer discussion of absorbance changes accompanying any other possible reactions - - these quantities will be needed only for more qualitative considerations.

\section{Calculations Using the "Simplest" Model for the Titration System}

As noted above, the least complicated analysis of RNA titration data over the $\mathrm{pH}$ range from 7.0 to 2.6 must incorporate at least five processesthe opening of $\mathrm{A} \cdot \mathrm{U}$ and $\mathrm{G} \cdot \mathrm{C}$ base pairs and the protonation of $\mathrm{A}, \mathrm{C}$, and G residues. ${ }^{7}$ We have pointed out that this model is probably not sufficiently complex to account for RNA titration behavior. Nevertheless, we shall perform calculations using this "simplest" model both to introduce our new procedure and to check that the computation method is sensitive enough to warrant use of a more complicated model. Thus, since hydrogen binding to $\mathrm{A}$ is not observed spectrophotometrically, we may attempt to analyze the optical data by writing Eq. (1) for each of four wavelengths and solving for the four unknowns, $\Delta \xi_{i}$. But before this can be done we must briefly clarify our nomenclature.

The absorbance data has all been converted to that for a solution having a standard concentration of $10^{-4} M[\mathrm{P}]$. From the overall base composition of $E$. coli rRNA (Ref. 6, p. 40) we find that the concentrations of the four bases are

$$
\begin{aligned}
& C_{\mathrm{C}}=0.218 \times 10^{-4} M \\
& \mathrm{C}_{\mathrm{G}}=0.322 \times 10^{-4} M \\
& C_{\mathrm{A}}=0.250 \times 10^{-4} M \\
& C_{\mathrm{U}}=0.210 \times 10^{-4} M
\end{aligned}
$$

We define the fractions of reaction, $\Delta \xi_{i}$, as follows, where $\Delta$ refers to the difference between the extent at the $\mathrm{pH}$ in question and the extent at $\mathrm{pH} 7$.

$\Delta \xi_{\mathrm{CH}}, \Delta \xi_{\mathrm{GH}^{+}}=$change in the fraction of protonated $\mathrm{C}$ or $\mathrm{G}$ residues

$-\Delta \xi_{\mathrm{GC}}=$ change in the fraction of $\mathrm{C}$ residues which are involved in $\mathrm{G} \cdot \mathrm{C}$ base pairs

$-\Delta \xi_{\mathrm{AU}}=$ change in the fraction of $\mathrm{A}$ residues which are involved in A. U base pairs 
The reason for defining $\Delta \xi_{\mathrm{GC}}$ and $\Delta \xi_{\mathrm{AU}}$ in this way is that while each term in Eq. (1) contains a concentration factor as well as a $\Delta \xi_{i}$ factor, we do not have very accurate knowledge of the actual numbers of $\mathrm{G} \cdot \mathrm{C}$ and A.U base pairs at $\mathrm{pH}$ 7. By defining $\Delta \xi_{\mathrm{GC}}$ and $\Delta \xi_{\mathrm{AU}}$ as above, we can use $C_{\mathrm{C}}$ and $C_{\mathrm{A}}$ as the concentration factors, which elimirutes uncertainty in the $C_{i}$ values for the base-pair openings. Note that we now must use $\epsilon_{\mathrm{GC}}^{\lambda}$ and $\epsilon_{\mathrm{AU}}^{\lambda}$ per base pair, as given in Table I.

Thus we have

$$
\begin{aligned}
\Delta A_{\lambda}=\left(C_{\mathrm{C}_{\mathrm{CH}}^{\lambda}}^{\lambda}\right) \cdot \Delta \xi_{\mathrm{CH}^{+}}+\left(C_{\left.\mathrm{G}^{\prime} \epsilon_{\mathrm{GH}^{+}}^{\lambda}\right) \cdot \Delta \xi_{\mathrm{GH}^{+}}}\right. & +\left(C_{\mathrm{C}}^{\lambda} \epsilon_{\mathrm{GC}}^{\lambda}\right) \cdot \Delta \xi_{\mathrm{GC}}+\left(C_{\mathrm{A}} \epsilon_{\mathrm{AU}}^{\lambda}\right) \cdot \Delta \xi_{\mathrm{AU}}
\end{aligned}
$$

Using values for $\epsilon_{i}^{\lambda}$ in Table I and $C_{i}$ values for our standard solution $\left([\mathrm{P}]=10^{-4} M\right)$ we can write, for the six wavelengths at which measurements were taken:

$$
\begin{array}{ll}
\Delta A_{300}=0.087 \Delta \xi_{\mathrm{CH}}+0.050 \Delta \xi_{\mathrm{GH}^{+}} \\
\Delta A_{290}=0.172 \Delta \xi_{\mathrm{CH}}+0.060 \Delta \xi_{\mathrm{GH}}+ & 0.052 \Delta \xi_{\mathrm{GC}} \\
\Delta A_{280}=0.133 \Delta \xi_{\mathrm{CH}}+ & 0.140 \Delta \xi_{\mathrm{GC}} \\
\Delta A_{270}=0.041 \Delta \xi_{\mathrm{CH}}+0.030 \Delta \xi_{\mathrm{GH}}+ & 0.122 \Delta \xi_{\mathrm{GC}}+0.127 \Delta \xi_{\mathrm{AU}} \\
\Delta A_{265}= & 0.081 \Delta \xi_{\mathrm{GC}}+0.203 \Delta \xi_{\mathrm{AU}} \\
\Delta A_{260}=-0.028 \Delta \xi_{\mathrm{CH}}+ & 0.072 \Delta \xi_{\mathrm{GC}}+0.216 \Delta \xi_{\mathrm{AU}}
\end{array}
$$

The four unknowns, $\Delta \xi_{i}$, can be evaluated at each $\mathrm{pH}$ value by solving (exactly) any four of Eqs. (2). A short computer program was used to solve the simultaneous equations at every $0.2 \mathrm{pH}$ unit over the $\mathrm{pH}$ range 7.0-2.6. The usefulness of the five process model was assessed by considering the magnitudes and trends of the $\Delta \xi_{i}$ as functions of $\mathrm{pH}$ according to the foollwing criteria:

High pH Range. From $\mathrm{p} K$ values given earlier (4.7 for C, 4.2 for A, 2.8 for $G$ ) we may conclude that there are essentially no protons bound to $\mathrm{C}, \mathrm{A}$, or $\mathrm{G}$ residues at $\mathrm{pH} 7$. In the range from $\mathrm{pH} 7$ to $\mathrm{pH} 5$ we expect to see a small degree of protonation of $\mathrm{A}$ and $\mathrm{C}$, with little opening of base pairs. $^{3}$

Low pH Range. For a double-stranded RNA, Cox et al. ${ }^{35}$ have found that the (sharp) helix-coil transition at $25^{\circ} \mathrm{C}, 0.1 M \mathrm{Na}+$ buffer, occurs very near to $\mathrm{pH} 3$, which implies that at the lowest $\mathrm{pH}(=2.6)$ in our rRNA experiments there should exist virtually no A.U or G.C base pairs. Since the simple model being considered does not allow for formation of any alternative structures, then all $\mathrm{A}, \mathrm{C}$, and $\mathrm{G}$ residues must be in amorphous regions at low $\mathrm{pH}$. From the $\mathrm{p} K$ values we see that $\mathrm{A}$ and $\mathrm{C}$ residues should be about $90-100 \%$ protonated at $\mathrm{pH} 2.6$, while $\mathrm{G}$ residues should be $40-60 \%$ protonated (i.e., $\Delta \xi_{\mathrm{AH}^{+}}$and $\Delta \xi_{\mathrm{CH}^{+}}=0.9-1.0, \Delta \xi_{\mathrm{GH}^{+}}=0.4-$ 0.6). This estimate checks with the experimental value for $\Delta \xi_{\mathrm{GH}}+$ at low $\mathrm{pH}$, which was calculated by extrapolating the $\mathrm{H}^{+} /[\mathrm{P}]$ data to $\mathrm{pH} 2.6$, then subtracting off the contributions from $\mathrm{CH}^{+}$and $\mathrm{AH}^{+}$(assuming these 
bases to be $90-100 \%$ protonated) and a small correction for protons bound to phosphate residues.

From the estimates of RNA helix content at $\mathrm{pH} 7^{2,4,6}$ we may assume that about $70 \%$ of the bases are involved in double helixes, and that about $55 \%$ of these base pairs are G.C. Thus, for every 1,000 bases, 700 are paired ( 350 base pairs), with $350 \times 0.55=192$ being $\mathrm{G} \cdot \mathrm{C}$ and the remainder (158) being $\mathrm{A} \cdot \mathrm{U}$ base pairs. Of the 1,000 bases, 218 are $\mathrm{C}$ and 250 are $\mathrm{A}$ residues. At $\mathrm{pH} 7$ then, the fraction of $\mathrm{C}$ residues in $\mathrm{G} \cdot \mathrm{C}$ base pairs is $192 / 218=0.88$, and the fraction of $\mathrm{A}$ residues involved in $\mathrm{A} \cdot \mathrm{U}$ pairs is $158 / 250=0.63$. If all base pairs are opened at $\mathrm{pH} 2.6$, then at this $\mathrm{pH}$ we expect $\Delta \xi_{\mathrm{GC}} \simeq 0.88$ and $\Delta \xi_{\mathrm{AU}} \simeq 0.63$.

Intermediate $\mathbf{p H}$ Range. We cannot, a priori, predict any $\Delta \xi_{i}$ values for the $\mathrm{pH}$ range 5-3 but at all $\mathrm{pH}$ 's we require that the extents of $\mathrm{A}, \mathrm{C}$, and $\mathrm{G}$ protonation be consistent with the $\mathrm{p} K$ 's of the bases in amorphous stretches and with our estimates (using $\Delta \xi_{\mathrm{GC}}$ and $\Delta \xi_{\mathrm{AU}}$ ) of the total numbers of bases in single-stranded regions.

Variation of $\Delta \xi_{i}$, with $\mathbf{p H}$. We require that $\Delta \xi_{i}$ change fairly smoothly. Rather steep transitions may be expected, but sinusoidal type curves for $\Delta \xi_{i}$ versus $\mathrm{pH}$ are unacceptable.

The computer program was used to solve for each of the four unknowns, $\Delta \xi_{i}$, using data at four wavelengths. The calculations were performed for both $I=0.1 M$ and $I=0.01 M$ results, and different sets of four wavelengths were used, but in no case were the appropriate criteria satisfactorily fulfilled. It was not considered proper to vary the values of the extinction coefficients since the data could surely have been fit with sixteen adjustable parameters. Nevertheless, calculations were made with various values of $\epsilon_{\mathrm{CH}}+$ at $\lambda=300 \mathrm{~m} \mu$ (due to some uncertainty in its value as mentioned above) and also with $\epsilon_{i}^{\lambda}$ values slightly different from those in Table I to see what effect these changes had on the results. Again, the results were unsatisfactory. In general, the computations yielded negative values for $\Delta \xi_{\mathrm{GC}}$ at high $\mathrm{pH}$, and failed to give any meaningful trends at lower $\mathrm{pH}$. The final values for $\Delta \xi_{i}$ at low $\mathrm{pH}$ were not close to those expected. (Use of a higher value for $\epsilon_{\mathrm{CH}^{+}}^{300}\left(\simeq 6 \times 10^{3}\right)$ did bring $\Delta \xi_{\mathrm{GC}}$ close to zero at high $\mathrm{pH}$, but this is probably only fortuitous because the calculations made without using $\lambda=300 \mathrm{~m} \mu$ all give unsatisfactory results.) In short, our calculations reveal that, as expected, the "simplest" model does not explain the experimental data, and thus our analytical procedure appears to be sufficiently sensitive to justify using a more complex model.

\section{Calculations Using a More Complex Model}

Computation Procedure. If we assume that in our "simplest" model we have omitted one process, we can incorporate this proposed reaction into our optical analysis by writing, for each wavelength,

$$
\Delta A_{\lambda}=\sum_{i=1}^{4} C_{i} \epsilon_{i}^{\lambda} \cdot \Delta \xi_{i}+X_{\lambda} \Delta \xi_{x}
$$


where $\Delta \xi_{x}$ is the extent to which the as yet unspecified reaction has occurred and $X_{\lambda}$ is the increment which this reaction adds to the absorbance at each wavelength. The summation is over the four reactions of the "simplest" model. At a given $\mathrm{pH}, \Delta \xi_{x}$ has the same value for all wavelengths. We cannot evaluate $X_{\lambda}$ and $\Delta \xi_{x}$ separately, but can determine only their product. Nevertheless, we will make use of the shape of the $X_{\lambda}$ difference spectrum even though we cannot determine its absolute magnitude.

Our first impulse was to choose a possible reaction, to deduce its expected $X_{\lambda}$ difference spectrum from data in the literature and to solve, at each $\mathrm{pH}$, five equations of type (3) for the five unknowns, $\Delta \xi_{i}$ and $\Delta \xi_{x}$. However, each set of $X_{\lambda}$ which we tried failed to give acceptable results at all $\mathrm{pH}$ values. Because our criteria for acceptability are, in the mathematical sense, somewhat subjective, it was not possible to systematize the procedure of guessing the $X_{\lambda}$ difference spectrum and then solving simultaneous equations.

Therefore, we took the following approach. Eqs. (3) were written formally, for each of five wavelengths. The actual values for the known coefficients $C_{i} \epsilon_{i}^{\lambda}$ were not inserted; rather, these quantities, along with the as yet unknown $X_{\lambda}$, were represented literally, except that those $C_{i} \epsilon_{i}^{\lambda}$ which were previously taken as zero (Table I) were set equal to zero to make the algebra somewhat more tractable. By the usual and laborious method of Cramer's rule, the equations were solved for the five unknowns, $\Delta \xi_{i}$ and $\Delta \xi_{x}$, in terms of the coefficients (including $X_{\lambda}$ ) and the measured absorbances, $\Delta A_{\lambda}$.

Let us first consider the algebraic solutions for $\Delta \xi_{i}$ (where $i \Leftrightarrow \mathrm{CH}^{+}$, $\mathrm{GH}^{+}, \mathrm{GC}$, or $\left.\mathrm{AU}\right)$. These quantities may be expressed in the form

$$
\Delta \xi_{i}=\frac{f_{i}\left(\left\{C_{j} \epsilon_{j}^{\lambda}\right\},\left\{\Delta A_{\lambda}\right\}\right)-g_{i}\left(\left\{C_{j} \epsilon_{j}^{\lambda}\right\},\left\{\Delta A_{\lambda}\right\}\right) \times R_{i}}{K_{1}\left(\left\{C_{j} \epsilon_{j}^{\lambda}\right\}\right)+K_{2}\left(\left\{C_{j} \epsilon_{j}^{\lambda}\right\}\right) \times R_{i}}
$$

where

$$
R_{i}=\frac{f_{i}\left(\left\{C_{j} \epsilon_{j}^{\lambda}\right\},\left\{X_{\lambda}\right\}\right)}{g_{i}\left(\left\{C_{j} \epsilon_{j}^{\lambda}\right\},\left\{X_{\lambda}\right\}\right)}
$$

In Eq. (4a), $f_{i}$ and $g_{i}$ are functions of the set of known coefficients, $\left\{C_{j}{ }_{j}^{\lambda}\right\}$, for the four reactions of our "simplest" model, and also are linear functions of the set of measured absorbance differences $\left\{\Delta A_{\lambda}\right\}$, while $K_{1}$ and $K_{2}$ depend only on the known coefficients $\left\{C_{j} \epsilon_{j}^{\lambda}\right\}$. The factor $R_{i}$ is seen from Eq. (4b) to be the ratio of $f_{i}$ to $g_{i}$, except that wherever $\Delta A_{\lambda}$ might appear in $f_{i}$ or $g_{i}$ in Eq. (4a) it is replaced by $X_{\lambda}$. Thus, the entire dependence of $\Delta \xi_{i}$ on the unknown $X_{\lambda}$ difference spectrum is contained in $R_{i}$.

Our procedure then is to guess values of $R_{i}$ which give results for the $\Delta \xi_{i}$ which are satisfactory in terms of the criteria discussed earlier. It will be seen that in most cases the values of $\Delta \xi_{i}$ are quite sensitive to the choice of $R_{i}$, so that the $R_{i}$ can be determined within strict limits. Now, each $R_{i}$ is a function of the five unknown $X_{\lambda}$ coefficients. However, because it is not possible to determine the absolute values of the $\left\{X_{\lambda}\right\}$, 
we may arbitrarily fix the value of one $X_{\lambda}$, leaving us with four unknown $X_{\lambda}$, which can be evaluated from the four $R_{i}$ we have chosen. In this way, we extract the difference spectrum, $\left\{X_{\lambda}\right\}$, of the unknown reaction, from which we hope to deduce the nature of the reaction.

Finally, one can solve for the extent (in arbitrary units) of the extra reaction, which is of form

$$
\Delta \xi_{x}=\frac{1}{g_{i}\left(\left\{C_{j} \epsilon_{j}^{\lambda}\right\},\left\{X_{\lambda}\right\}\right)} \frac{K_{1} \cdot g_{i}\left(\left\{C_{j} \epsilon_{j}^{\lambda}\right\},\left\{\Delta A_{\lambda}\right\}\right)+K_{2} \cdot f_{i}\left(\left\{C_{j} \epsilon_{j}^{\lambda}\right\},\left\{\Delta A_{\lambda}\right\}\right)}{K_{1}+K_{2} \cdot R_{i}}
$$

where $i$ may correspond to any of the four reactions of the "simplest" model.

To make these ideas more concrete, it may be of value to give explicitly the form of the functions $K_{1}$ and $f_{i}$. Thus, using the five wavelengths $\lambda=$ $300,290,280,270$, and $265 \mathrm{~m} \mu$,

$$
\begin{aligned}
& K_{1}=\left(C_{\mathrm{C}^{2} \epsilon_{\mathrm{CH}^{+}}^{300}}\right)\left(C_{\mathrm{G}} \epsilon_{\mathrm{GH}^{+}}^{290}\right)\left(C_{\mathrm{C}} \epsilon_{\mathrm{GC}}^{280}\right)-\left(C_{\mathrm{G}} \epsilon_{\mathrm{GH}^{+}}^{300}\right)\left(C_{\mathrm{C}} \epsilon_{\mathrm{CH}^{+}}^{290}\right)\left(C_{\mathrm{C}} \epsilon_{\mathrm{GC}}^{280}\right) \\
& +\left(C_{\mathrm{G}} \epsilon_{\mathrm{GH}^{+}}^{300}\right)\left(C_{\mathrm{C}} \epsilon_{\mathrm{GC}}^{290}\right)\left(C_{\mathrm{C}_{\mathrm{CH}}}^{280}\right)
\end{aligned}
$$

( $K_{2}$ is similar but more complex and includes coefficients of the $\mathrm{A} \cdot \mathrm{U}$ reaction.)

As an example of the function $f_{i}$, we use $f_{\mathrm{CH}^{+}}$, for the cytosine protonation reaction. Then, using $\Delta A_{\lambda}$ values for the $\mathrm{pH}$ of interest,

$$
\begin{aligned}
& f_{\mathrm{CH}}+\left(\left\{C_{j} \epsilon_{j}^{\lambda}\right\},\left\{\Delta A_{\lambda}\right\}\right)=\Delta A_{300} \cdot\left(C_{\left.\mathrm{G}_{\mathrm{G}} \epsilon_{\mathrm{GH}^{+}}^{290}\right)\left(C_{\mathrm{C}} \epsilon_{\mathrm{GC}}^{280}\right)}\right. \\
& \quad-\Delta A_{290} \cdot\left(C_{\mathrm{G}} \epsilon_{\mathrm{GH}^{+}}^{300}\right)\left(C_{\mathrm{C}} \epsilon_{\mathrm{GC}}^{280}\right)+\Delta A_{280}\left(C_{\mathrm{G}} \epsilon_{\mathrm{GH}}^{300}\right)\left(C_{\mathrm{C}} \epsilon_{\mathrm{CG}}^{290}\right)
\end{aligned}
$$

( $g_{\mathrm{CH}}+$ is similar but more complex and includes coefficients of the A. U reaction as well as $\Delta A_{270}$ and $\Delta A_{265}$.)

Since the $R_{i}$ ratios contain $f_{i}$ and $g_{i}$ expressions similar to that of Eq. (7) (replacing $\Delta A_{\lambda}$ with $X_{\lambda}$ ) it is easy to see that the assignment of numerical values to the $R_{i}$ will lead to readily solvable linear equations in the $\left\{X_{\lambda}\right\}$.

This calculation procedure was applied to our absorbance data for RNA solutions of $0.1 M$ and $0.01 M$ ionic strength (Figs. 2 and 3). The proton binding data (Fig. 1) were used to compute the degree of adenine protonation. The quantities $f_{i}$ and $g_{i}$ in Eqs. (4a) were evaluated for each of the four processes of the "simplest" model by using the extinction coefficients from Table $I$ and the appropriate $\Delta A_{\lambda}$ values from Figures 2 and 3 at $\lambda=$ $300,290,280,270$, and $265 \mathrm{~m} \mu$. Then the values of $\Delta \xi_{i}$ were computed at $\mathrm{pH}$ intervals of 0.2 unit for a series of choices of $R_{i}$. The criteria applied to the "simplest" model calculations could be used to determine the final choices of $R_{i}$ here because (a) it is likely that any acid-stable structure will not hinder proton binding to $\mathrm{A}, \mathrm{C}$, or $\mathrm{G}$, since formation of such structures is encouraged by protonation of these residues ${ }^{31,33}$ and (b) we assume that regardless of any acid-stable structures which may be formed at low $\mathrm{pH}$, virtually all $\mathrm{GC}$ and $\mathrm{AU}$ base pairs will have opened at $\mathrm{pH} 2.6^{35}$ so that we again have $\Delta \xi_{\mathrm{GC}} \simeq 0.8$ and $\Delta \xi_{\mathrm{AU}} \simeq 0.6$. 
TABLE II

Final Choices for the Quantities $R_{i}$ (Acid Branch Titrations)

\begin{tabular}{|c|c|c|c|}
\hline & \multicolumn{2}{|c|}{$I=0.1 M$} & \multirow{2}{*}{$\begin{array}{c}I=0.01 M \\
\quad \text { All } \mathrm{pH}\end{array}$} \\
\hline & High $\mathrm{pH}$ & Low pH & \\
\hline$R_{\mathrm{CH}^{+}}$ & 1.20 & 1.31 & 1.31 \\
\hline$R_{\mathrm{GH}^{+}}$ & 1.28 & 1.41 & 1.41 \\
\hline$R_{\mathrm{GC}}$ & 0.70 & 0.90 & 0.90 \\
\hline$R_{\mathrm{AU}}$ & 1.05 & 1.20 & 1.20 \\
\hline
\end{tabular}

After the final choices were made for $R_{\mathrm{CH}}+R_{\mathrm{GH}}, R_{\mathrm{GC}}$, and $R_{\mathrm{AU}}$, the $X_{\lambda}$ difference spectrum was computed by assigning the value $X_{300}=+0.100$ and solving four simultaneous equations of form

$$
h_{i}\left(X_{290}, X_{280}, X_{270}, X_{265}\right)=R_{i}
$$

Finally, $\Delta \xi_{x}$ was calculated using Eq. (5).

A further check on the results was obtained from the data at an additional wavelength, $\lambda=260 \mathrm{~m} \mu$. Using Eq. (3) for $\lambda=260 \mathrm{~m} \mu$ and having determined the $\Delta \xi_{i}$ and $\Delta \xi_{x}$, one can solve for $X_{260}$ at each $\mathrm{pH}$. This coefficient should fit reasonably well with the $\left\{X_{\lambda}\right\}$ at the other wavelengths, and $X_{260}$ should not vary with $\mathrm{pH}$ (unless the $R_{i}$ are chosen to be functions of $\mathrm{pH}$ ).

Results of the Calculations. Eq. (4a) shows that the $\Delta \xi_{i}$ are expressed as fractions, in which $R_{i}$ appears in both numerator and denominator. For the extinction changes given in Table I, the functional form of $\Delta \xi_{i}$ causes the calculated $\Delta \xi_{i}$ to be quite sensitive to the choice of $R_{i}$; thus, a change in $R_{i}$ of $\pm 5 \%$ causes a significant shift in the $\Delta \xi_{i}$ values. The final choices of $R_{i}$ are displayed in Table II. We see that one set of $R_{t}$ values is adequate to account for the $I=0.01 M$ data at all $\mathrm{pH}$ 's. However, this is not the case for the $I=0.1 M$ results, for which we present two sets of $R_{i}$, one which fits the data at low $\mathrm{pH}$, and one which fits the data at higher $\mathrm{pH}$. The need for two sets of $R_{i}$ at $I=0.1 M$ was anticipated above when we pointed out that the existence of hysteresis leads us to expect an acid-stable structure at low $\mathrm{pH}$, while at higher $\mathrm{pH}$ an unexpected structure, not necessarily the same as the low $p H$ structure, seems necessary to explain the data. It is important to note that the $R_{i}$ values for the $I=$ $0.01 M$ data are the same as those which describe the $I=0.1 M$ data at low $\mathrm{pH}$, while the $R_{i}$ values for the $I=0.1 M$ results at high $\mathrm{pH}$ give unsatisfactory results for the $I=0.01 M$ case.

Calculated values for the quantities $\Delta \xi_{i}$ are shown in Figures 4 and 5 . Figure 4 gives $\Delta \xi_{\mathrm{AH}}+$ computed with the help of the $I=0.1 M$ proton binding data (we have not measured $\mathrm{H}^{+} /[\mathrm{P}]$ at $I=0.01 M$ ). The results at $I=0.1 M$ (Fig. 4) were derived using the "low-pH" set of $R_{t}$ for $\mathrm{pH} 3.0$ 2.6, and the "high-pH" set of $R_{i}$ for $\mathrm{pH}>3.8$, while the $\Delta \xi_{i}$ at $\mathrm{pH} 3.6-3.2$ were evaluated using averages of these $R_{i}$ 's. This procedure is based on the observation that the hysteresis sets in only if one titrates with acid to 

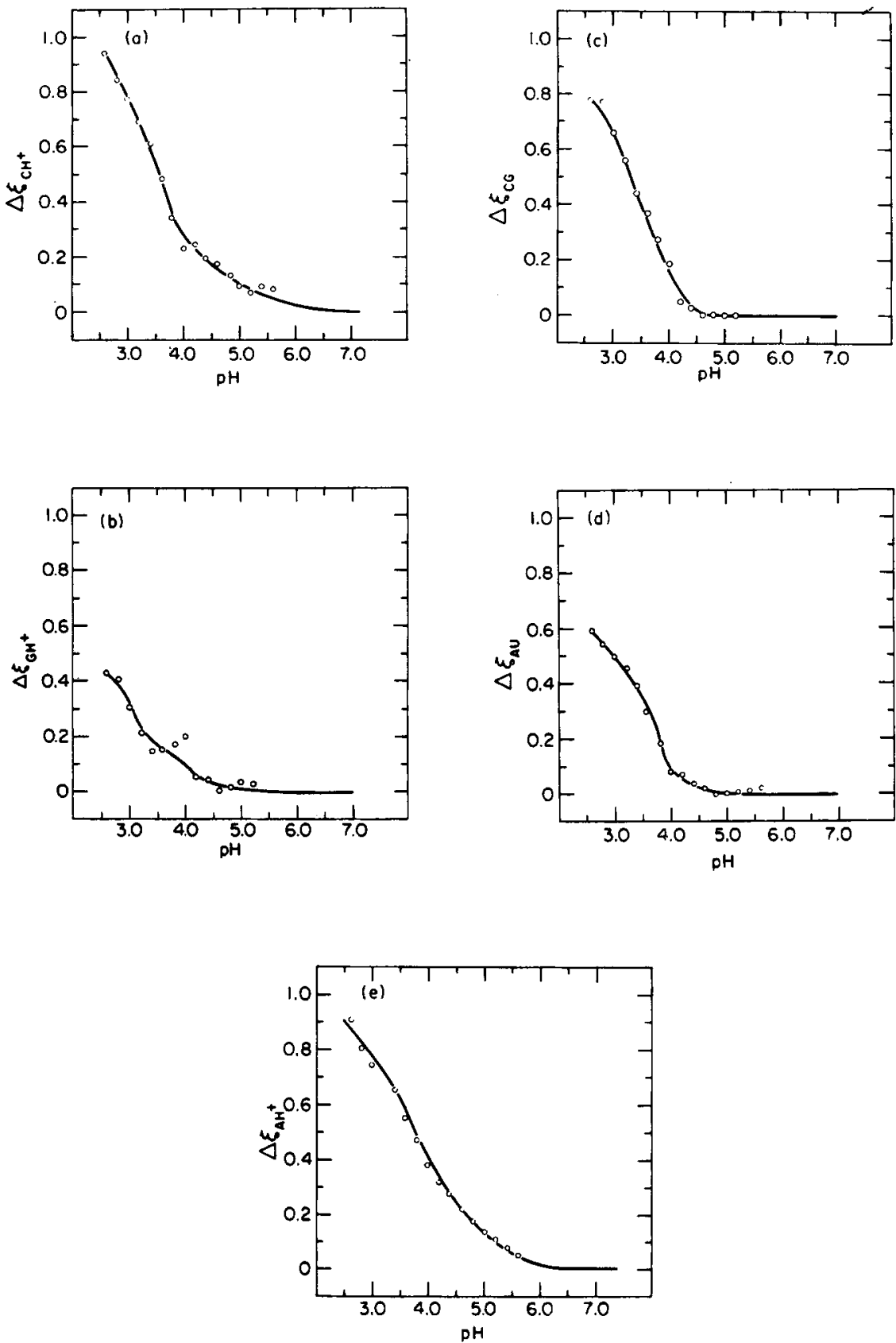

Fig. 4. Results of calculations for $I=0.1 M$ solution (acid branch). These graphs show the changes in extent of reaction for the five processes of the "simplest" titration model. The symbols $O$ are the calculated values at every $0.2 \mathrm{pH}$ unit, the lines are drawn by eye through these points. 

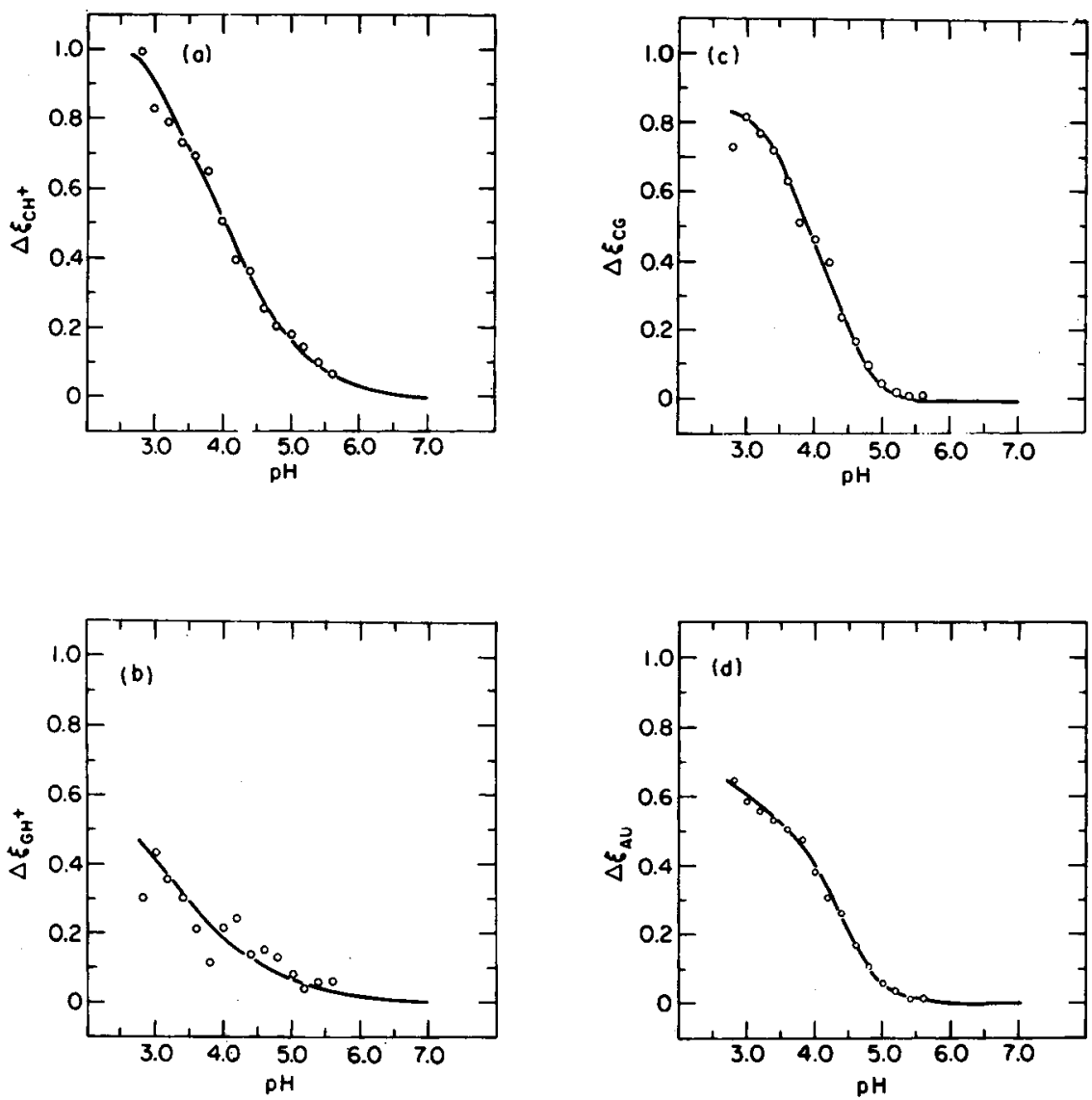

Fig. 5. Results of calculations for $I=0.01 M$ solution (acid branch). These graphs show the changes in extent of reaction for four processes of the "simplest" model. (Lack of proton binding data at $I=0.01 M$ prevented evaluation of $\Delta \xi_{\mathrm{AH}}{ }^{+}$) The symbols $\mathrm{O}$ are the calculated values at every $0.2 \mathrm{pH}$ unit, the lines are drawn by eye through these points.

$\mathrm{pH}<3.8$. We assume that formation of the low $\mathrm{pH}$ structure is responsible for the hysteresis effect ${ }^{1}$ and thus this structure is not present above $\mathrm{pH}$ 3.8. We also assume that the high-pH structure is likely to disappear at lower $\mathrm{pH}$-we somewhat arbitrarily take it to be totally eliminated by $\mathrm{pH}$ 3.0. In the $\mathrm{pH}$ range 3.6-3.2, we assume that there exists a mixture of the two structures.

Figure 6 shows the difference spectra of the "extra" reactions, calculated using the two sets of $R_{i}$. The extents of the "extra" reactions, $\Delta \xi_{x}$ (in arbitrary units), for the two ionic strengths are shown in Figure 7.

Before we discuss the interpretation of these results in terms of possible RNA conformations, it is worthwhile to consider how much faith we can place in these detailed numerical calculations. We first consider the reliability of the $R_{i}$ values. It has been noted that for any acceptable 


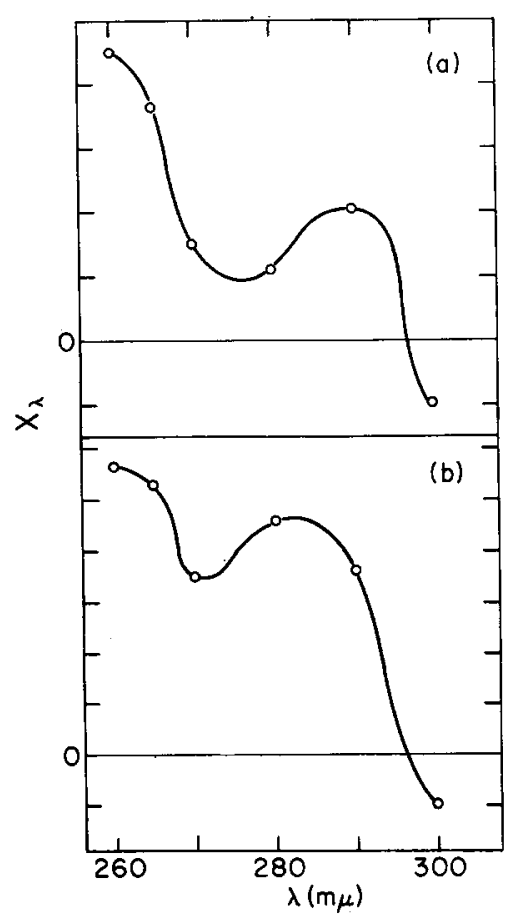

Fig. 6. Spectral changes (in arbitrary units) accompanying the proposed "extra" reactions. Curve (a) corresponds to the structure formed at low $\mathrm{pH}$ in $I=0.1 \mathrm{M}$ solution and at all $\mathrm{pH}$ values in $I=0.01 \mathrm{M}$ solution. Curve (b) corresponds to the structure formed at high $\mathrm{pH}$ in $I=0.1 M$ solution. For both spectra the magnitude of $X_{3 c 0}$ has been taken to be 0.100 ; note that vertical scales for curves (a) and (b) are not identical. As drawn, curves (a) and (b) imply that $X_{\lambda}$ represent changes upon dissociation of the "extra" structure (and thus correspond to the data in Figure 8).

set of $\Delta \xi_{i}$ values, the $R_{i}$ computed using the extinction changes in Table I are known to better than $\pm 5 \%$. The $\{X \lambda\}$ difference spectra in Figure 6 are not qualitatively modified by variations in $R_{i}$ of this magnitude.

The computations of $X_{260}$ provide an independent check which increases our confidence in our procedures. First, we find that $X_{260}$ does not vary substantially with $\mathrm{pH}$ for the $I=0.01 M$ calculations. Furthermore, this $X_{260}$ value is within $10 \%$ of the value extracted from analysis of the $I=$ $0.1 M$ data at low $\mathrm{pH}$, which implies that the results at the two ionic strengths are consistent. It can be inferred from Figure 6 that this $X_{260}$ value differs considerably from that for the high $\mathrm{pH}$ structure formed in $I=0.1 M$ solution.

To check the sensitivity of the $R_{i}$ values to our choices of extinction changes, a series of calculations was made in which all but one $C_{i} \epsilon_{i}^{\lambda}$ value were taken from Table I, while the odd $C_{i} \epsilon_{i}^{\lambda}$ was changed by $\pm \mathbf{0 . 0 1 0}$. These computations in general showed that no significant changes in $R_{i}$ are needed even if the values of $C_{i} \epsilon_{i}^{\lambda}$ in Table $I$ are not exactly correct. In any event, the $C_{i} \epsilon_{i}^{\lambda}$ values in Table $I$ were deduced before the $R_{i}$ 


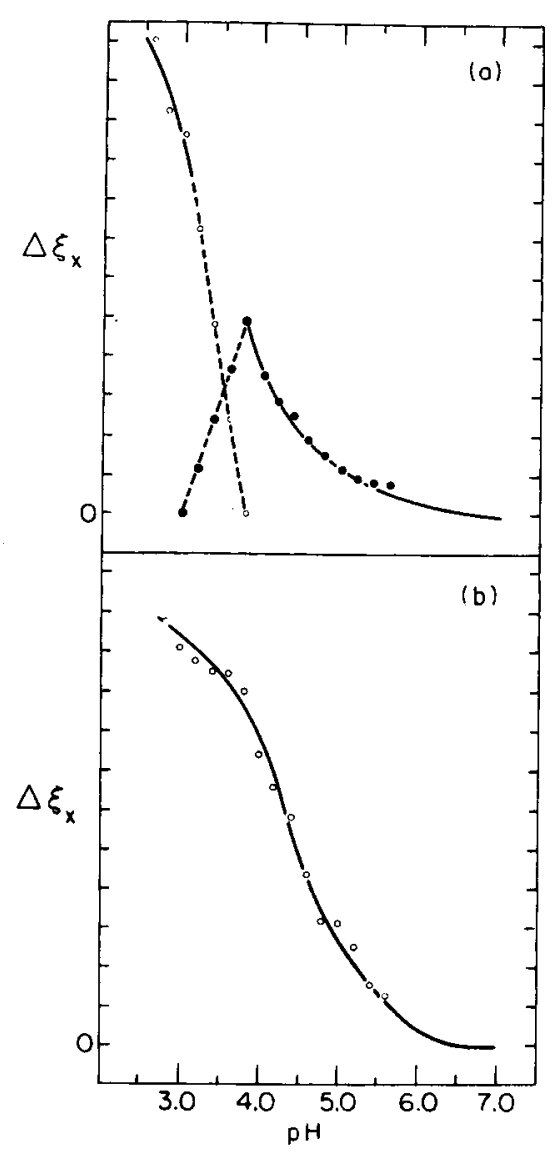

Fig. 7. Extents of the proposed "extra" reactions (in arbitrary units). (a) $I=0.1 M$ solution. Symbols - are for the "high-pH" structure, $O$ for the "low-pH" structure. It is assumed that above pH 3.8 only the "high-pH" structure is formed and that this structure disappears at lower $\mathrm{pH}$. We arbitrarily take it to be fully eliminated at $\mathrm{pH}$ 3.0. Below $\mathrm{pH} 3.0$, only the "low-pH" structure is present. For $3.0<\mathrm{pH}<3.8$ a mixture of structures is assumed to exist. It is not possible to determine the absolute magnitudes of the $\Delta \xi_{x}$; thus the $\bullet$ and $O$ values are not necessarily directly comparable, since they may correspond to different vertical scales. (b) $I=0.01 M$ solution.

analysis was attempted, and it is gratifying that these coefficients lead to sets of $R_{i}$ which satisfactorily account for our data.

The results presented in Figures 4, 5, and 7 quantitatively describe, in full, the acidic titration behavior of rRNA. It is clear that the numerical values we have given may be improved as better values for the extinction changes become available, and as more is learned about the assumption of additivity of optical effects, stacking, etc. While we will not at this time make further use of our $\Delta \xi$ results, we nevertheless feel that the calculations are of value as an illustration of the power of our computation method. Although there are four $R_{i}$ parameters which may be adjusted, the requirements imposed on these $R_{i}$ are quite stringent. We have con- 
fidence in the actual numbers we have derived, first because these were the result of combining data from careful spectrophotometric and potentiometric measurements, and second because the results can be reasonably interpreted on the basis of RNA conformations which can quite possibly exist in acidic solution.

\section{Analysis of the "Base Branch" of the Titration Cycle $(I=0.1 M)$}

The calculation procedures we have used to analyze RNA structural changes upon titration with acid from $\mathrm{pH} 7 \mathrm{can}$, in principle, be applied to the base branch of the hysteresis loop. Using data given in a previous paper, ${ }^{1}$ we first verified that the "simplest" model cannot account for the base branch results. We then attempted an analysis using the two sets of $R_{i}$ deduced for the $I=0.1 M$ acid titration, one set corresponding to the high-pH and the other to the low-pH situation. However, the data are such that both sets of $R_{i}$ give acceptable values for the $\Delta \xi_{i}$ as functions of $\mathrm{pH}$. Our analysis of the acid branch was aided by the observation that the titration is reversible down to $\mathrm{pH} 3.8$. No such useful handle is available for treating the base branch-we were unable to discern a reversible region on the base branch, so we could not determine if there is a $\mathrm{pH}$ range in which only one of the two proposed acid-stable structures is present. We conclude then that processes in addition to those of the "simplest" model are surely needed to account for the base branch titration data. We can calculate an average value for the extents of these reactions, but for the time being it is not possible to compute the relative amounts of high-pH or low-pH structure present at each $\mathrm{pH}$ value on the base branch

\section{INTERPRETATION OF RESULTS}

There are a number of polynucleotide conformations known from studies on model systems which might account for our RNA titration results. We will consider as possibilities the formation at acidic $\mathrm{pH}$ of double-helical sequences containing protonated $\mathrm{A} \cdot \mathrm{A}, \mathrm{C} \cdot \mathrm{C}$, or $\mathrm{G} \cdot \mathrm{G}$ base pairs, or of triple-stranded regions involving $C$ and $G$ residues. The formation of $\mathrm{A} \cdot 2 \mathrm{U}$ triple helixes in rRNA is unlikely at low $\mathrm{pH}$, as will be discussed below. We wish to compare the derived difference spectra for the "extra" reactions (Fig. 6) with the absorbance changes accompanying the above-mentioned possible reactions, which are shown in Figure 8. The spectra in Figure 8 represent absorbance changes due to the "extra" reactions alone. The optical effects of any proton binding which may accompany the reaction have been deducted, since these contributions to the measured absorbance are already contained in the summation term in Eq. (3).

\section{Proposed Structures in $I=0.1 M$ (Low $\mathrm{pH}$ ) and in $I=0.01 M$ Solutions}

Cox and Katchalsky, ${ }^{38}$ in their description of hysteresis in rRNA, have discussed the possibility of $\mathrm{A} \cdot \mathrm{A}$ and $\mathrm{C} \cdot \mathrm{C}$ formation at low $\mathrm{pH}$, while Mitra and Kaesberg ${ }^{39}$ invoke $\mathrm{C} \cdot \mathrm{C}$ structures to explain the $\mathrm{pH}$-dependence 


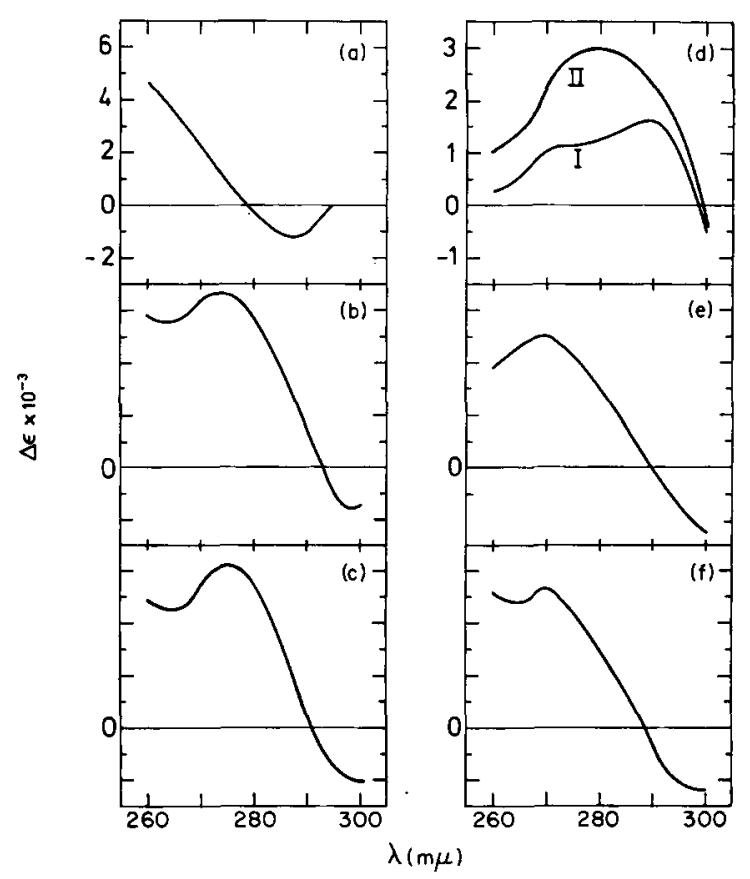

Fig. 8. Spectral changes, derived from literature data, for "extra" reactions which could take place during rRNA titration. (a) Dissociation of A.A.base pairs (the reaction helix $\rightarrow$ unstacked coil). Derived from the work of Helmkamp and Ts'o [Biochim. Biophys. Acta, 55, 601 (1962)] and also by combining data of Fresco and Klemperer ${ }^{30}$ and of Steiner and Beers ${ }^{16}$ with that of Voet et al. [Biopolymers, 1, 193 (1963)]. Contributions from double helix unwinding and from destacking are roughly equal in magnitude at all wayelengths. Thus, this curve gives the shape of the absorbance difference spectrum for the dissociation of A.A base pairs into either the stacked or unstacked conformation. (b) Dissociation of G.G base pairs. ${ }^{13}$ (c) Dissociation of GGGC aggregates [S. K. Podder, Eur. J. Biochem., 22, 467 (1971)]. (d) Dissociation of C.C base pairs. Curve I represents spectral changes which accompany the reaction poly $(C) \cdot \operatorname{poly}(\mathrm{C}) \rightarrow$ 2 poly $(\mathrm{C})$ (stacked) after correction for absorbance changes due to deprotonation of $\mathrm{C}$ residues. ${ }^{33}$ Curve II is the difference spectrum for opening of C.C base pairs to unstacked single-stranded residues (derived by combining curve I with data of Helmkamp and Ts'o for single-strand poly (C) destacking [Biochim. Biophys. Acta, 55, 601 (1962)]. (e) Dissociation of poly $(C)+$ GMP complex [M.-Th. Sarocchi, Y. Courtois, and -W. Guschlbauer, Eur. J. Biochem., 14, $411(1970)]$. (f) Dissociation of $2 \mathrm{C}: 1 \mathrm{G}$ complex. ${ }^{52}$

of the sedimentation coefficient for TYMV RNA (which is rich in cytosine residues). (Abbreviation used: TYMV RNA denotes the ribonucleic acid from turnip yellow mosaic virus.) However, we feel that $\mathrm{C} \cdot \mathrm{C}$ regions are not likely to persist in $I=0.1 M$ solution at $\mathrm{pH} 2.6$ because the results of Hartman and $\operatorname{Rich}^{33}$ imply that the $\operatorname{poly}(\mathrm{C}) \cdot \operatorname{poly}(\mathrm{C})$ double helix is destabilized at $\mathrm{pH} \leq 3$, and any oligo $\mathrm{C}$-oligo $\mathrm{C}$ stretches in RNA should be even less stable than the longer polymers. The 2 poly $(\mathrm{A})=$ poly(A) $\cdot \operatorname{poly}(\mathrm{A})$ coil-helix transition is reversible, ${ }^{40,41}$ so it seems unlikely that $A \cdot A$ rich regions can account for the hysteresis properties of rRNA. Nevertheless, the formation of such structures in rRNA at low $\mathrm{pH}$ is a 
definite possibility. It is likely that $A \cdot A$ regions increase in stability at low $\mathrm{pH}$, since the melting temperature of $\operatorname{poly}(\mathrm{A}) \cdot \operatorname{poly}(\mathrm{A})$ appears to increase monotonically with the degree of protonation. ${ }^{42}$

We wish to call attention to the possibility of forming $G \cdot G$ rich regions at low $\mathrm{pH}$. We have proposed elsewhere ${ }^{\mathrm{l}}$ that double-helical stretches rich in $G \cdot G$ base pairs may be responsible for the hysteresis observed for rRNA. It is of interest that both $16 \mathrm{~S}$ and $23 \mathrm{~S} E$. coli rRNA molecules possess a large percentage of $\mathrm{G}$ residues, ${ }^{6}$ so that G-rich stretches may well be available for reaction. The recent work of Fellner and associates ${ }^{43-45}$ on the sequencing of $16 \mathrm{~S} E$. coli $\mathrm{rRNA}$ reveals the presence of sequences of seven to ten $G$ residues interrupted only once by a different base, and of even longer regions consisting only of $A$ and $G$ residues. These workers also demonstrate the existence of $(\mathrm{A}, \mathrm{G})$-rich homologous sequences in $E$. coli rRNA.

Furthermore, direct evidence concerning the spectral changes for the low $\mathrm{pH}$ reaction has been obtained. ${ }^{1}$ We may attribute absorbance differences at $80^{\circ} \mathrm{C}$ between iso- $\mathrm{pH}$ solutions on different branches of the hysteresis loop to the spectral changes which characterize formation of the low $\mathrm{pH}$ structure. The difference spectrum in Figure 6a, deduced from our analysis of titration data at $T=20^{\circ} \mathrm{C}$, is consistent with the difference spectra in Figures $7 \mathrm{a}$ and $7 \mathrm{~b}$ of Ref. 1, which were derived from the results at $T=80^{\circ} \mathrm{C}$. Comparing these spectra with that given in Figure $8 \mathrm{a}$ shows that spectral changes for the low-pH reaction cannot be explained by the formation of $\mathrm{A} \cdot \mathrm{A}$ base pairs alone. However, the low-pH difference spectrum is seen to resemble the spectra for reactions involving $G$ residues [Fig. 8 (b,c,e,f)] and is consistent with a combination of spectra for A.A and $\mathrm{G} \cdot \mathrm{G}$ formation.

We conclude, then, that all evidence taken together strongly indicates that the structure formed at low $\mathrm{pH}$ in $I=0.1 M$ solution is a mixture of protonated $\mathrm{G} \cdot \mathrm{G}$ and $\mathrm{A} \cdot \mathrm{A}$ regions, in which a major contribution arises from the guanine helixes.

At $I=0.01 M, \mathrm{C} \cdot \mathrm{C}$ double helixes might be stable at $\mathrm{pH} 2.8$, since these structures are stabilized at lower ionic strength. ${ }^{33}$ However, the fact that the titration results for $I=0.01 M$ can be explained with the $X_{\lambda}$ difference spectrum corresponding to the $\mathrm{G} \cdot \mathrm{G}$ and $\mathrm{A} \cdot \mathrm{A}$ structures proposed for $I=$ $0.1 M$, low $\mathrm{pH}$, coupled with the relatively low percentage of $\mathrm{C}$ residues in $E$. coli $\mathrm{rRNA}$ leads us to conclude that $\mathrm{C} \cdot \mathrm{C}$ structures are absent at $I=$ $0.01 M$. At low ionic strength, then, only $\mathrm{G} \cdot \mathrm{G}$ and $\mathrm{A} \cdot \mathrm{A}$ helixes form, and these begin to appear at even higher $\mathrm{pH}$ values (see Fig. 7b) than in $I=$ $0.1 M$ solution.

\section{Proposed Structure at $I=0.1 M($ High pH)}

Our high $\mathrm{pH}$ results apparently can be explained only by invoking another "extra" reaction. Comparison of the $X_{\lambda}$ difference spectrum in Figure $6 \mathrm{~b}$ with the spectra in Figure 8 leads us to consider that this additional $h i g h-p H$ structure also involves guanine residues. 
Let us first deal with other possible structures which could conceivably form. One might propose that structural reorganizations at high $\mathrm{pH}$ result in a net formation of $\mathrm{A} \cdot \mathrm{U}$ or $\mathrm{G} \cdot \mathrm{C}$ base pairs as the $\mathrm{pH}$ is decreased. However, since both of these structures are destabilized in acid medium, it does not seem that such processes should be facilitated by lowering the $\mathrm{pH}$. The formation of $\mathrm{A} \cdot 2 \mathrm{U}$ triple helixes by addition of a sequence of $\mathrm{U}$ residues to a pre-existing $A \cdot U$ region is not likely in acid medium. ${ }^{41,46}$ Studies on model systems suggest that $A \cdot 2 U$ triple helixes in rRNA might possibly be formed by rearrangement of two A.U double-stranded regions, to yield $\mathrm{A} \cdot 2 \mathrm{U}$ plus a stretch of single-stranded protonated A residues. ${ }^{47,48}$ However, this reaction shows only a very small absorbance change at $\lambda=$ $260 \mathrm{~m} \mu$ and thus cannot explain our experimental observations.

The formation of $\mathrm{A} \cdot \mathrm{A}$ or $\mathrm{C} \cdot \mathrm{C}$ base pairs is also unlikely in RNA at high $\mathrm{pH}$, even through the homopolynucleotides undergo coil-helix transitions at $\mathrm{pH} 5.5-6.0 .^{33,46}$ The $X_{\lambda}$ difference spectrum calculated for the high-pH structure is not consistent with spectral changes upon formation of A.A sequences (Fig. 8a) or of C.C sequences (Fig. 8d). While a combination of $\mathrm{A} \cdot \mathrm{A}$ and $\mathrm{C} \cdot \mathrm{C}$ rich regions might account for our absorbance data, we note that at $\mathrm{pH} 7$ there are very few $\mathrm{C}$ residues in single-stranded regions, so it is not probable that significant amounts of $\mathrm{C} \cdot \mathrm{C}$ double strand can be formed. Furthermore, qualitative considerations also weigh against $\mathrm{A} \cdot \mathrm{A}$ or $\mathrm{C} \cdot \mathrm{C}$ regions being the high-pH "extra" structure. X-ray analysis has shown that the strands in poly (A) poly(A) and poly $(\mathrm{C}) \cdot-$ poly $(C)$ are parallel, ${ }^{34,49}$ while the Watson-Crick base pairing which predominates in RNA at high $\mathrm{pH}$ involves anti-parallel strands. Our calculations predict that the "unknown" structure at high $\mathrm{pH}$ is formed before substantial numbers of $\mathrm{A} \cdot \mathrm{U}$ and $\mathrm{G} \cdot \mathrm{C}$ base pairs have been opened. This observation, along with the compactness of the RNA molecule at $\mathrm{pH} 7$ as revealed by electron microscopy (see Ref. 50, and also A. Revzin, submitted for publication) implies that it may not be sterically feasible for structures involving parallel strands to be formed at high $\mathrm{pH}$. We note that these considerations are relevant to yet another possible high-pH process, namely the reaction of two $A \cdot U$ rich sequences to form an $A .2 U$ triple helix plus a double-helical A-A stretch. ${ }^{48,51}$ This would involve rather extensive strand rearrangements, and seems unlikely in view of the probable difficulty in forming parallel A.A double helixes.

We are thus led to consider possible structures involving $G$ residues. Relatively little is known about the conformations which oligo $G$ and poly $(G)$ can assume in solution. It is known that both the oligomers and polymers tend to aggregate to extremely stable helical structures, but the number and parallelism of the strands has not been determined. Lipsett ${ }^{52}$ has shown that poly(C) and oligo G's form triple helixes. A number of schemes are possible for $\mathrm{G} \cdot \mathrm{G}$ base pairing, but in the absence of $\mathrm{X}$-ray data we cannot predict whether the strands are parallel or anti-parallel (or whether both are possible). It is also conceivable that acid-stable $\mathrm{G} \cdot \mathrm{G}$ structures can be formed with the bound proton either directly involved in 
(a)

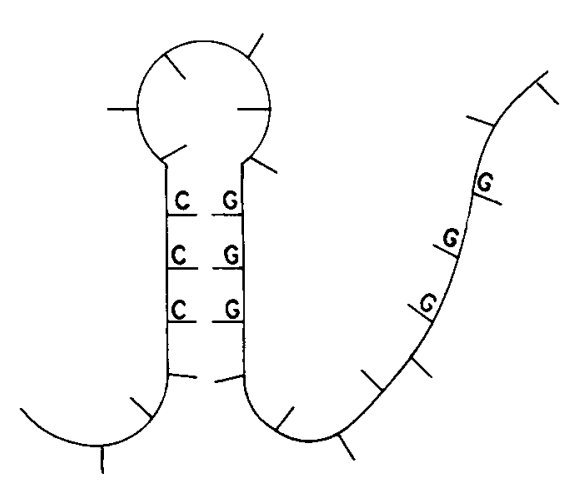

(b)

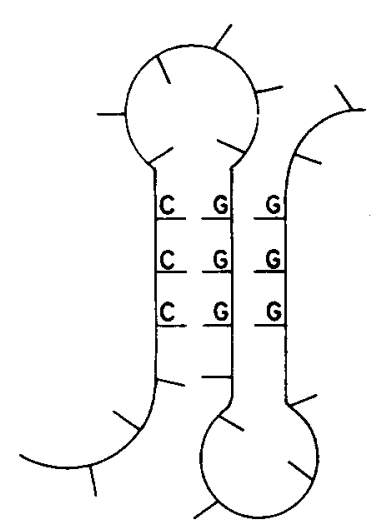

Fig. 9. Hypothetical model showing how the proposed "high-pH" G.C.G triplestrand might form. Structure (b) presumably is stable only if protons are bound to some $\mathrm{G}$ (or C) residues (hence (b) does not form at $\mathrm{pH} 7$ ). The $\mathrm{G}$ strands in (b) are seen to be anti-parallel. If $C$ and $G$ are interchanged in the base-paired region of (a) we obtain a structure of type (b) in which the G strands are parallel.

a hydrogen bond (as in poly $(\mathrm{C}) \cdot \operatorname{poly}(\mathrm{C})$ ) or else serving to stabilize the structure through electrostatic interaction with the backbone of the opposite strand (as in poly (A) - poly(A)). Finally, while the $\mathrm{p} K$ of $\mathrm{G}$ is quite low, acid-stable structures could be formed even at $\mathrm{pH} 5-6$ (as seen from the fact that poly $(\mathrm{C})$ and poly(A) form double helixes at $\mathrm{pH}$ values far above the $p K$ values of their amorphous forms). In this regard it is noteworthy that the titration data of Thiele and Guschlbauer ${ }^{28}$ reveal that poly $(\mathrm{G})$ binds considerably more protons at $\mathrm{pH} 5$ than would be expected from a $\mathrm{pK}$ of 2.8 for guanine residues in single-stranded polynucleotides. In short, there are no serious contradictions to our proposal that acid-stable conformations involving $\mathrm{G}$ are assumed by RNA in the $\mathrm{pH}$ range $7-5$.

We propose that the "extra" structure at high $\mathrm{pH}$ consists of triplestranded regions involving guanine residues. Because of the predominance of $\mathrm{G}$ residues in $E$. coli $\mathrm{rRNA}$, such triple helixes may be of the $2 \mathrm{G}: 1 \mathrm{C}$ type. Podder ${ }^{53}$ has shown that oligo $\mathrm{G}$ can interact with poly $(\mathrm{C})$ to form $2 \mathrm{G} \cdot 1 \mathrm{C}$ complexes. Figure 9 indicates how such conformations in rRNA might arise by association of neighboring single- and double-strand segments. It is clear from reversing the $\mathrm{C}$ and $\mathrm{G}$ residues in the base-paired region of Figure $9 \mathrm{a}$ that such a scheme allows the $\mathrm{G}$ strands to be parallel or anti-parallel to each other. A triple-stranded polymer complex of stoichiometry $2 \mathrm{C}: 1 \mathrm{G}$ has been reported at acid $\mathrm{pH}$ by Thiele and Guschlbauer. ${ }^{28}$ We cannot reject this as a possible RNA conformation, except to observe that $\mathrm{C}$ is present in $E$. coli RNA in considerably smaller amounts than is $G$. Studies on systems containing short $C$ and $G$ chains indicate that oligomeric complexes of $\mathrm{G}$ and $\mathrm{C}$ tend to be triple- rather than doublestranded. ${ }^{52,53}$ We also note from Figure 9 that a $G \cdot G \cdot C$ structure formed 
at high $\mathrm{pH}$ could easily rearrange to give the $\mathrm{G} \cdot \mathrm{G}$ low-pH structure which we have discussed above. The failure to form the proposed triple-helical structure in medium of lower ionic strength is attributed to high electrostatic repulsion between the phosphate backbones in the triple strand. It may also be that RNA has less tertiary structure at high $\mathrm{pH}$ at $I=0.01 \mathrm{M}$ than in $I=0.1 M$ solution, which may hinder the association of the regions to form triple strands. Such effects should overcome any tendency for $\mathrm{H}^{+}$phosphate electrostatic attraction to stabilize the proposed multistrand structure at low ionic strength.

We might also consider the possibility that the "extra" structure at high $\mathrm{pH}$ is double-stranded. For this we need to invoke anti-parallel $\mathbf{A} \cdot \mathbf{A}$ or C.C structures (which have never been observed), or else anti-parallel $\mathrm{G} \cdot \mathrm{G}$ double helixes. This last possibility cannot be eliminated a priori, but it should be noted that if such structures do form, they are probably not the same G.G stretches we have proposed to explain the results for $\mathrm{pH}$ $<3.8$. The fact that the low-pH structure can exhibit metastability, while the high- $\mathrm{pH}$ structure does not, indicates that these conformations are likely to be considerably different.

\section{CONCLUSIONS}

In the course of an investigation of RNA hysteresis we have developed a new method to quantitatively analyze the titration behavior of RNA. This analysis shows that as the $\mathrm{pH}$ is lowered there is a substantial amount of acid-stable structure formed (at ionic strengths of $0.1 M$ and $0.01 M$ ). In $I=0.1 M$ solution, there is an "extra" structure formed in the $\mathrm{pH}$ range 6-4. On the basis of properties of model systems, we have proposed that this structure is a triple helix composed of $1 \mathrm{C}$ and $2 \mathrm{G}$ strands. As the $\mathrm{pH}$ is decreased below 3.8, the "high-pH" structure is replaced by a different acid-stable conformation. We propose that this structure, which can exhibit metastability, consists mainly of $\mathrm{G} \cdot \mathrm{G}$ and $\mathrm{A} \cdot \mathrm{A}$ double-helical regions. In solutions of lower ionic strength $(I=0.01 M)$ no triplestranded structure is seen; only the proposed $G \cdot G$ and $A \cdot A$ double helixes are formed as the $\mathrm{pH}$ is decreased.

Our calculations yield predictions for the spectral changes which characterize the proposed "extra" reactions. These results are consistent with experimental difference spectra obtained previously. ${ }^{1}$

The procedures we have developed permit us to calculate, at each $\mathrm{pH}$, the extents of A, C, and G protonation, of $\mathrm{A} \cdot \mathrm{U}$ and $\mathrm{G} \cdot \mathrm{C}$ base pair opening, and of acid-stable structure formation. More important than these numbers may be the implications we can draw about the structure of RNA under physiological-like conditions. For example, the triple strand we have proposed at $\mathrm{pH} 5$ could conceivably be formed at $\mathrm{pH} 7$ in conjunction with the cooperative binding of proteins, and thus might contribute to ribosome conformation. "Native tertiary structure" of ribosomes, ${ }^{6}$ tRNA ${ }^{10,54,55}$ and $5 \mathrm{~S} \mathrm{RNA}^{9}$ has been invoked to explain experimental findings, but its 
nature has yet to be elucidated. We suggest that in appropriate cases, heretofore unpredicted base-base interactions involving $\mathrm{G}$ residues may be a factor in these "tertiary" structures.

Note added in proof. We wish to call attention to the recent work of Slegers and Fiers (Biopolymers 12, 2007 (1973)), who have characterized a metastable conformation of MS2 RNA in acid medium. They discuss structures which may be responsible for the fast-sedimenting MS2 RNA particle which is formed at $\mathrm{pH} 3.8$ under their conditions.

The authors wish to thank Dr. N. R. Kallenbach for comments on the manuscript. This work was supported, in part, by a National Science Foundation postdoctoral fellowship (granted to A.R.) and by a grant from the Stiftung Volkswagenwerk (to E.N.).

\section{APPENDIX : SEDIMENTATION COEFFICIENTS A'T ACIDIC pH FOR $E$. coli rRNA}

\section{ARNOLD REVZIN}

To supplement our titration studies of rRNA, sedimentation coefficients $(S)$ were determined as a function of $\mathrm{pH}$. There has been a multitude of previous studies of the sedimentation properties of RNA, many of these dealing with the magnitudes of $S$ values for the " $16 S^{\prime}$ " and " $23 S^{\prime}$ " species of rRNA.6.56-59 The presence of divalent cations such as $\mathrm{Mg}^{++}$has a marked effect on the measured sedimentation coefficients (for review see Ref. 6, p. 34). Variation of $S$ with $\mathrm{pH}$ has been investigated by Mitra and Kaesberg ${ }^{39}$ for TYMV RNA, and by Studier ${ }^{60}$ for denatured (single-stranded) DNA.

\section{Experimental}

Sedimentation coefficients were determined using a Beckman Model E ultracentrifuge equipped with ultraviolet optics and a photoelectric scanner. The rotor speed was $32,000 \mathrm{rpm}$ and the rotor temperature was maintained at $20^{\circ} \mathrm{C}$.

A stock solution was prepared of $10^{-4} M[\mathrm{P}] \mathrm{rRNA}$ in $\mathrm{pH} 7$ buffer containing $0.099 M$ $\mathrm{NaCl}, 0.001 M \mathrm{Na}$ cacodylate. Immediately prior to the sedimentation run, an aliquot of RNA solution was made either $2 \times 10^{-4} \mathrm{M}$ in $\mathrm{Mg}^{++}$ions or $5 \times 10^{-4} \mathrm{M}$ in EDTA, and the solution was then titrated to the desired $\mathrm{pH}$. For $\mathrm{pH}$ values in the range $3.5 \leq$ $\mathrm{pH} \leq 4.8,50 \mu \mathrm{l}$ of acetate buffer $\left(0.1 M\right.$ in $\left.\mathrm{Na}^{+}\right)$at the appropriate $\mathrm{pH}$ were added to the titrated solution to insure constant $\mathrm{pH}$ during the sedimentation run. Since all experiments were performed using the same RNA stock solution, the nucleotide concentration was the same for all runs, except for 3-5\% dilution during titration. In any case, variation of $S$ with RNA concentration is very small at the low concentrations used here, so that the measured $S$ values can be taken as equal to the values at infinite dilution. ${ }^{39,56}$ Sedimentation runs were made on $\mathrm{pH} 7$ solutions at the beginning and at the end of a series of $S$ versus $\mathrm{pH}$ measurements. Boundary analysis of sedimentation data for these solutions showed no measurable degradation of RNA in the stock solution in the time during which the series of measurements was made.

\section{Results}

Figure 10 shows the results of a typical sedimentation boundary analysis. It is seen that traces taken at different times during the run yield the same results. This indicates that diffusion effects on the boundary are negligible and also provides a check that the centrifuge cell developed no leaks during the run. The RNA is seen to be slightly heterodisperse, with the smaller particles presumably arising from limited hydrolysis of the 


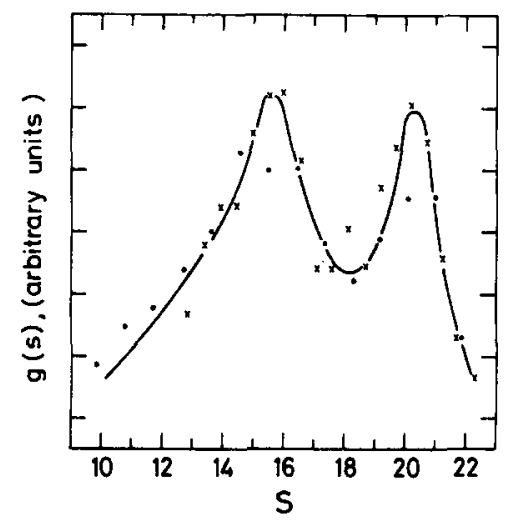

Fig. 10. Typical distribution of $S$ values in a sedimentation experiment. The distribution function, $g(S)$, is discussed by Schachman. ${ }^{61}$ Symbols $\bullet$ denote values from a scan at 52 minutes after the start of the run, symbols $X$ are for a scan taken 88 minutes after the start. The $S$ values are taken to be 20.5 for the faster moving component and 15.5 for the slower component. These data are for a solution at $\mathrm{pH} 3.7,0.1 \mathrm{M} \mathrm{Na}{ }^{+}$, $2 \times 10^{-4} M \mathrm{Mg}^{++}, T=20^{\circ} \mathrm{C}$.

nucleic acid during purification and preparation of solutions. Nevertheless, two sharp sedimenting peaks are clearly resolvable.

The $S$ values corresponding to the maximum values of the distribution function, $g(S)$ (see Fig. 10), ${ }^{61}$ are taken to be the sedimentation coefficients of the two primary RNA species-these values are plotted in Figure 11 for the several pH's at which runs were performed. The $S$ values were converted to $S_{20, w}$ in the usual way, using the value 0.54 $\mathrm{ml} / \mathrm{g}$ as the partial specific volume for RNA. The precision of the $S$ values so derived is about $\pm 0.5 \mathrm{~S}$ unit, based on reproducibility of scans at different times during a run and on the results from repeated measurements at the same $\mathrm{pH}$. The (interpolated) values of $S$ at about $\mathrm{pH} 4.5$ check very closely with those given by Taylor et al., ${ }^{58}$ who report measurements in a solvent containing $0.1 M \mathrm{NaCl}, 0.01 M$ EDTA, $20 \mu \mathrm{g} / \mathrm{ml}$ poly(vinyl sulfate), at $\mathrm{pH} 4.5$. It is noteworthy that above $\mathrm{pH} 3.5$ there is little difference in $S$ values between solutions containing $\mathrm{Mg}^{++}$ions and solutions containing EDTA (which were thus $\mathrm{Mg}^{++}$-free). At pH 3.5 and 3.0 , it is seen that $S$ values in solutions containing $\mathrm{Mg}^{++}$ions were about $2 \mathrm{~S}$ units higher than the values in solutions to which EDTA had been added.

\section{Discussion}

The observation that very nearly the same $S$ values are obtained in the presence or absence of $\mathrm{Mg}^{++}$(at $\mathrm{pH}>3.5$ ) confirms our conclusions from ultraviolet absorbance data that structural changes occurring in RNA upon titration with acid are not markedly affected by removing or adding small concentrations of $\mathrm{Mg}^{++}$ions (in solutions of $I=$ $\left.0.1 M \mathrm{Na}^{+}\right){ }^{2}$ Larger values for $\mathrm{S}$ in $\mathrm{Mg}^{++}$-containing solutions at low $\mathrm{pH}$ are presumably due to changes in tertiary structure, which are not seen optically. We also reported that RNA does not show hysteresis in the absence of $\mathrm{Mg}^{++}$ions, which implies that divalent ions may stabilize the hysteresis through specific interactions with certain regions of the RNA molecule. Further studies may help to clarify the extent to which the larger $S$ values observed at $\mathrm{pH} 3.5$ and 3.0 in the presence of $\mathrm{Mg}^{++}$are due to a nonspecific electrostatic effect of $\mathrm{Mg}^{++}$or to specific interactions of $\mathrm{Mg}^{++}$ions with RNA helical regions, including the metastable conformation.

Turning to the variation of $S$ with $\mathrm{pH}$ we see that for both the "16S" and "23S" RNA species $S$ decreases relative to its $\mathrm{pH} 7$ value in the $\mathrm{pH}$ range $5-4$, then increases 


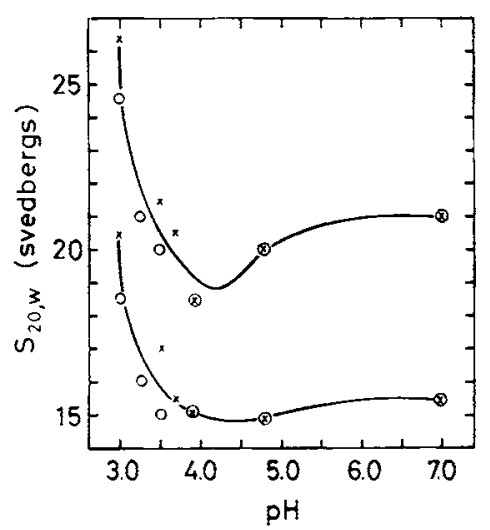

Fig. 11. $S$ versus pH for $E$. coli rRNA. Upper curve, $S_{20, w}$ for " $23 S^{\prime}$ " $E$. coli rRNA, lower curve, $S_{20, w}$ for " $16 \mathrm{~S}$ " $E$. coli $r$ RNA. Estimated uncertainty in $S$ values is $\pm 0.5 \mathrm{~S}$ unit. Experimental conditions: $0.099 M \mathrm{NaCl}, 0.001 M \mathrm{Na}$ cacodylate, plus $2 \times 10^{-4} M$ $\mathrm{MgCl}_{2}$ (symbols $X$ ) or $5 . \times 10^{-4} M$ EDTA (symbols $O$ ). In the $\mathrm{pH}$ range $3.5 \leq \mathrm{pH} \leq$ $4.8,50 \mu \mathrm{l}$ of acetate buffer $\left(0.1 \mathrm{M} \mathrm{Na}{ }^{+}\right)$were added to stabilize the $\mathrm{pH}$. The RNA concentration was $\sim 10^{-4} M[\mathrm{P}]$.

so that $S$ at $\mathrm{pH} 3$ is considerably higher than the pH 7 value (Fig. 11). The increase in $S$ at low $\mathrm{pH}$, which has also been seen for denatured $\mathrm{DNA}^{80}$ is particularly striking. RNA at pH 7 is known to have about $70 \%$ of its bases in double-helical regions and thus should be a rather compact hydrodynamic entity, ${ }^{6}$ while at $\mathrm{pH} 3$ most residues are in single-stranded stretches. Nevertheless, it seems that the uncoiled RNA molecule can assume a shape more compact than that of the $\mathrm{pH} 7$ molecule. Neither the "primary charge effect" 62 nor changes in the degree of "counterion binding" $63-65$ can account for the larger $S$ value at low $\mathrm{pH}$. On the other hand, the coiling of single-stranded regions will be aided by the reduction in electrostatic repulsion between different sections of the polymer chain, due to charge neutralization which accompanies protonation of the bases. Furthermore, electron microscopy results (Ref. 50 and also A. Revzin, sulmitted for publication) indicate that the $\mathrm{pH} 7$ molecule has substantial tertiary structure, which may keep the RNA in a more extended configuration at $\mathrm{pH} 7$ than would otherwise be likely. Thus, the coiling of neutralized single strands plus the presence of $\mathrm{pH} 7$ tertiary structure may combine to cause $S$ at $\mathrm{pH} 3$ to exceed $S$ at $\mathrm{pH} 7$.

The decrease in $S$ in the pH range 5-4 indicates that the RNA has become more extended than it was at neutrality. The calculations presented in the main body of this paper as well as other studies ${ }^{3}$ imply that at $\mathrm{pH} 4$ only a rather small fraction of $\mathrm{A} \cdot \mathrm{U}$ and $\mathrm{G} \cdot \mathrm{C}$ base pairs have opened (relative to the $\mathrm{pH} 7$ molecule). The effect on $S$ of a small degree of unwinding at $\mathrm{pH} 4$ cannot be predicted a priori. We have observed that single-stranded regions can, under appropriate conditions, assume a configuratic which leads to an $S$ value higher than that for a mostly double-helical molecule. On the other hand, if the single strands formed by unwinding are sterically hindered from assuming a coiled form (perhaps due to the presence of other base-paired regions) then unwinding could result in a less compact molecule having a lower $S$ value,

Another factor in the decrease of $S$ at pH 5-4 may be the formation of the proposed "high-pH" structure in rRNA. If this structure is, in fact, of the G C C G type as shown in Figure 9 above, then formation of the triple-stranded regions would restrict the flexibility of the RNA. This could result in a more rod-like molecule having a correspondingly lower $S$ value. We also note that the increase in $S$ at $\mathrm{pH} 3$ could be enhanced by the proposed "low-pH" structure consisting of (G.G, A.A) rich sequences. These structures, which are present only to a fairly low extent, could help the RNA at pH 3 to assume a compact shape, without seriously hindering the ability of the single-strand 
regions to coil. In short, our sedimentation results are consistent with the formation of the triple-strand and double-strand structures which have been proposed to explain the spectrophotometric titration data at high and at low $\mathbf{p H}$.

The author wishes to thank Dr. Jamie Godfrey for invaluable instruction in the techniques of sedimentation analysis.

\section{References}

1. A. Revzin, E. Neumann and A. Katchalsky, J. Mol. Biol., 79, 95 (1973).

2. R. A. Cox, Biochem. J., 98, 841 (1966).

3. R. A. Cox, Biochem. J., 100, 146 (1966).

4. P. Doty, H. Boedtker, J. R. Fresco, R. Haselkorn, and M. Litt, Proc. Natl. Acad. Sci. (U.S.), 45, $482(1959)$.

5. S. Arnott, F. Hutchinson, M. Spencer, M. H. F. Wilkins, W. Fuller, and R. Langridge, Nature, 211, 227 (1966).

6. A. S. Spirin and L. P. Gavrilova, The Ribosome, Springer-Verlag, Berlin (1969).

7. R. A. Cox and U. Z. Littauer, Biochim. Biophys. Acta, 72, 188 (1963).

8. R. A. Cox, Quart. Rev. Chem. Soc., 22, 499 (1968).

9. G. Bellemare, R. J. Cedergren, and G. H. Cousineau, J. Mol. Biol., 68, 445 (1972).

10. R. N. Goldstein, S. Stefanovic, and N. R. Kallenbach, J. Mol. Biol., 69, 217 (1972).

11. J. Clauwaert and J. Stockx, Z. Naturf $\_$rsch., 23b, 25 (1968).

12. A. Katchalsky, Z. Alexandrowicz, and $\mathrm{O}$. Kedem, in Chemical Physics of Ionic Solutions, B. E. Conway and R. G. Barradas, Eds., John Wiley, New York (1966), p. 295.

13. F. Pochon and A. M. Michelson, Proc. Natl. Acad. Sci. (U.S.), 53, 1425 (1965).

14. R. A. Cox, Biochem. J., 117, 101 (1970).

15. H. J. Gould and S. Simpkins, Biopolymers, 7, 223 (1969).

16. W. B. Gratzer, Biochim. Biophys. Acta, 123, 431 (1966).

17. H. Boedtker, Biochem., 6, 2718 (1967).

18. H. Simpkins and E. G. Richards, Biochem., 6, 2513 (1967).

19. J. Brahms, A. M. Aubertin, G. Dirheimer, and M. Grunberg-Manago, Biochem., 8, 3269 (1969).

20. C. R. Cantor and I. Tinoco, Jr., J. Mol. Biol., 13, 65 (1965).

21. G. Felsenfeld and S. Z. Hirschman, J. Mol. Biol., 13, 407 (1965).

22. S. M. Coutts, Biochim. Biophys. Acta, 232, 94 (1971).

23. J. R. Fresco, L. C. Klotz, and E. G. Richards, Cold Spring Harbor Symp. Quant. Biol., 28, 83 (1963).

24. E. G. Richards and S. Simpkins, Eur. J. Biochem., 6, 93 (1968).

25. A. Rich and I. Tinoco, Jr., J. Am. Chem. Soc., 82, 6409 (1960).

26. R. A. Cox, Biochem. $J$., 120, 539 (1970).

27. M. Chamberlin, R. L. Baldwin, and P. Berg, J. Mol. Biol., 7, 334 (1963).

28. D. Thiele and W, Guschlbauer, Biopolymers, 10, 143 (1971).

29. G. H. Beaven, E. R. Holiday, and E. A. Johnson, in The Nucleic Acids, Vol. I,

E. Chargaff and J. N. Davidson, Eds., Academic Press, New York (1955), p. 493.

30. J. R. Fresco and E. Klemperer, Ann. N.Y. Acad. Sci., 81, 730 (1959).

31. D. N. Holcomb and S. N. Timasheff, Biopolymers, 6, 513 (1968).

32. R. F. Steiner and R. F. Beers, Jr., Biochim. Biophys. Acia, 32, 166 (1959).

33. K. A. Hartman, Jr., and A. Rich, J. Am. Chem. Soc., 87, 2033 (1965).

34. R. Langridge and A. Rich, Nature, 198, 725 (1963).

35. R. A. Cox, K. Kanagalingam, and E. Sutherland, Biochem. J., 125, 655 (1971).

36. M. Gellert, M. N. Lipsett, and D. R. Davies, Proc. Natl. Acad. Sci. (U.S.), 48, 2013 (1962).

37. J. F. Chantot, M.-Th. Sarocchi, and W. Guschlbauer, Biochimie, 53, 347 (1971). 
38. R. A. Cox and A. Katchalsky, Biochem. J., 126, 1039 (1972).

39. S. Mitra and P. Kaesberg, J. Mol. Biol., 14, 558 (1965).

40. R. C. Warner and E. Breslow, Proc. 4th Int. Cong. Biochem., Vol. 9, Pergamon Press, New York (1958), p. 157.

41. E. Neumann and A. Katchalsky, Ber. Bunsenges. f. Phys. Chemie, 74, 868 (1970).

42. J. Massoulié, Compt. Rend. Acad. Sci., 260, 5554 (1965).

43. P. Fellner, C. Ehresmann, P. Stiegler, and J.-P. Ebel, Nature New Biology, 239, 1 (1972).

44. P. Fellner, C. Ehresmann, and J.-P. Ebel, Biochimie, 54, 853 (1972).

45. C. Ehresmann, P. Stiegler, P. Fellner, and J.-P. Ebel, Biochimie, 54, 901 (1972).

46. R. F. Steiner and R. F. Beers, Jr., J. Polymer Sci., 30, 17 (1958).

47. C. L. Stevens and G. Felsenfeld, Biopolymers, 2, 293 (1964).

48. J. Massoulié, Eur. J. Biochem., 3, 439 (1968).

49. A. Rich, D. R. Davies, F. H. C. Crick, and J. D. Watson, J. Mol. Biol., 3, 71 (1961).

50. A. S. Spirin, Macromolecular Structure of Ribonucleic Acids, Reinhold, New York (1964).

51. J. Clauwaert, Z. Naturforsch., 23b, 454 (1968).

52. M. N. Lipsett, J. Biol. Chem., 239, 1256 (1964).

53. S. K. Podder, Biopolymers, 11, 1395 (1972).

54. H. G. Zachau, Angew. Chem. Intern. Ed., 8, 711 (1969).

55. F. Cramer, Progr. Nucl. Acid Res. Mol. Biol., 11, 391 (1971).

56. C. G. Kurland, J. Mol. Biol., 2, 83 (1960).

57. W. M. Stanley, Jr., and R. M. Bock, Biochem., 4, 1302 (1965).

58. M. M. Taylor, J. E. Glasgow, and R. Storck, Proc. Natl. Acad. Sci. (U.S.), 57, 164 (1967).

59. A. Rodgers, Biopolymers, 9, 843 (1970).

60. F. W. Studier, J. Mol. Biol., 11, 373 (1965).

61. H. K. Schachman, Ultracentrifugation in Biochemistry, Academic Press, New York (1959).

62. K. O. Pedersen, J. Am. Chem. Soc., 62, 1282 (1958).

63. Z. Alexandrowicz and E. Daniel, Biopolymers, 1, 447 (1963).

64. Z. Alexandrowicz and E. Daniel, Biopolymers, 6, 1500 (1968).

65. A. Katchalsky, Pure Appl. Chem., 26, 327 (1971).

Received June 14, 1973

Revised September 10, 1973 